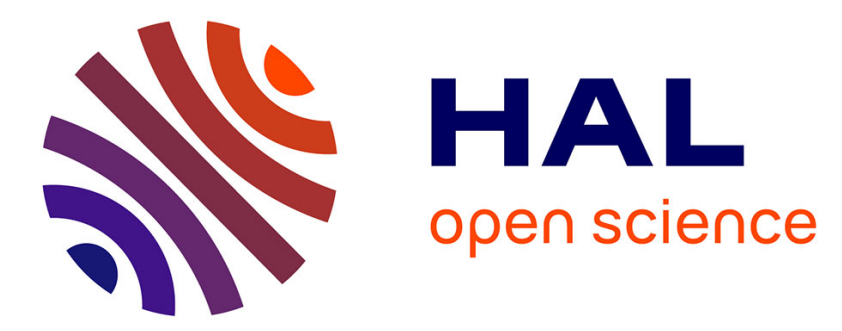

\title{
On the Dynamic Fragmentation of two Limestones using Edge-on Impact Tests
}

\author{
Sébastien Grange, Pascal Forquin, Stephan Mencacci, François Hild
}

\section{To cite this version:}

Sébastien Grange, Pascal Forquin, Stephan Mencacci, François Hild. On the Dynamic Fragmentation of two Limestones using Edge-on Impact Tests. International Journal of Impact Engineering, 2008, 35, pp.957-991. 10.1016/j.ijimpeng.2007.07.006 . hal-00322192

\section{HAL Id: hal-00322192 \\ https://hal.science/hal-00322192}

Submitted on 16 Sep 2008

HAL is a multi-disciplinary open access archive for the deposit and dissemination of scientific research documents, whether they are published or not. The documents may come from teaching and research institutions in France or abroad, or from public or private research centers.
L'archive ouverte pluridisciplinaire HAL, est destinée au dépôt et à la diffusion de documents scientifiques de niveau recherche, publiés ou non, émanant des établissements d'enseignement et de recherche français ou étrangers, des laboratoires publics ou privés. 


\title{
On the Dynamic Fragmentation of two Limestones using Edge-on Impact Tests
}

\author{
S. Grange ${ }^{a}$ P. Forquin ${ }^{b}$ S. Mencacci ${ }^{c}$ F. Hild ${ }^{a, *}$ \\ ${ }^{\mathrm{a}}$ LMT-Cachan/CNRS UMR 8535/University of Paris 6, 61 avenue du Président \\ Wilson, F-94235 Cachan Cedex, France \\ ${ }^{\mathrm{b}}$ LPMM/University of Metz, Ile du Saulcy, F-57045 Metz Cedex, France \\ ${ }^{\mathrm{c}}$ Nitrochimie, Usine la Dynamite, F-13310 St-Martin-de-Crau, France
}

\begin{abstract}
Two limestones are studied to compare the fragmentation pattern induced by dynamic loads. A quasi-static characterization allows one to determine the basic mechanical properties and to compare the two rocks in terms of Weibull parameters, indicators of microstructural differences. Edge-on impacts are performed and show the important role of the Weibull modulus in the fragmentation pattern. Simulations of these experiments are performed and validate the simple model proposed for rocks.
\end{abstract}

Key words: Damage model, Dynamic fragmentation, Poisson Point process, Weibull parameters

\section{Introduction}

A consequence of intense pulses or blasts on brittle materials is their fragmentation into discrete domains. For example, ceramics are multiply fragmented when impacted [1]. This class of materials has received some attention when used as a front layer of an armor [2,3]. Similarly, glass is used in armored windshields and experiences multiple fragmentation when impacted by debris or bullets [4,5]. Furthermore, since the pioneering work of Rinehart [6], it is known that the ultimate strength of rocks under so-called dynamic loading conditions exceeds the static strength by as much as one order of magnitude. The distinct zones resulting from rock blasting were identified by Kutter and

* to whom correspondence should be addressed

Email address: hild@lmt.ens-cachan.fr (F. Hild). 
Fairhurst [7], namely a comminuted area (or crushing zone) in the vicinity of the explosive followed by a damaged zone in which dense microcracking is observed and finally a zone where few long cracks develop. Later, it was recognized that inherent flaws are activated, grow and eventually coalesce to form macrocracks [8]. Similarly, concrete experiences multiple fragmentation when hit by a striker [9]. Yet, when loaded in tension or flexure under quasistatic conditions, all these materials usually experience single fragmentation and their failure strength is no longer deterministic.

The fragmentation process is discrete by essence. In the theory developed by Mott [10], the fragmentation of a rapidly expanding ring was studied. It contains some key ingredients (i.e., the randomness of the process is clearly stated and accounted for) to analyze the distribution of fragments in $2 \mathrm{D}$ experiments [11]. From a numerical point of view, discrete models are also proposed [12-15] when the fragment size is greater than or equal to the size of a representative element. Espinosa et al. [16] have developed a continuum/discrete multi-scale model in which the finer scale is discrete and allows for the derivation of a continuum description on a higher scale. Alternatively, Continuum Damage Mechanics is used with an isotropic [17-19] or anisotropic [20] damage description to account for multiple fragmentation. Consequently, in the numerical simulations, the medium is assumed to be continuum on the scale of a finite element in which numerous cracks are expected to form. However, crack densities may strongly vary over the structure and the analysis of fragmentation through a continuum modeling may be delicate when one or a few cracks are nucleated or propagate in certain zones. As an alternative, a multi-scale model has been developed in which the probabilistic aspect is treated within a damage model [21,22].

The paper focuses on the study of two different limestones, namely, a crinoidal limestone and the so-called "blanche de Beaucaire." These rocks are extracted from quarries. The mining and quarrying industries aim at controlling the block size distribution, namely, a big block cannot go through the crusher, while comminuted rock is inexploitable. An analysis and prediction of the fragmentation of blasted rocks is therefore desirable. The aim of the paper is to predict the dynamic fragmentation of two limestones. The parameters of the model are identified with quasi-static experiments. It will be shown that a simple identification procedure is sufficient to describe dynamic fragmentation. The Weibull model is used to describe different microstructures, and the Weibull parameters allow for the prediction of the crack density when dynamically loaded. Section 2 introduces the two rocks and their mechanical properties. This section also discusses how the microstructure is described by a Poisson-Weibull model. Then, dynamic experiments have been performed. Edge-on impacts are carried out and analyzed in Section 3. Based upon a fragmentation theory, a damage model [22] is summarized in Section 4. The experiments are then simulated. 


\section{Quasi-static experiments and microstructure characterization}

Beaucaire limestone is quarried in southern France and used in cement work. Crinoidal limestone comes from Belgium, and is utilized for gravestone or sculpture. These rocks have been chosen, first because of their availability, and also their significant difference, namely, Beaucaire limestone is porous and friable whereas crinoidal limestone is a hard rock. A microanalysis (Energy Dispersive Spectroscopy) of the two studied rocks shows different elements. A matrix of lime is observed. Inclusions made of silica, magnesia, sulphur, ferrous sulphide and potassium oxides are present in crinoidal limestone. Beaucaire limestone contains several inclusions of silica and alumina. This section aims at studying mechanical properties to compare the two rocks. The main results are gathered in Table 1. Only elementary tests are performed and reported herein. The following measurements were performed:

- mass density of eight samples by using Archimede's principle. A volume of the order of $3 \mathrm{~cm}^{3}$ is prepared. The mass is measured in open air $m_{1}$ and in demineralized water $m_{2}$. The density of demineralized water $\rho_{W}$ is known. The mass density $\rho$ then reads

$$
\rho=\frac{m_{1}}{m_{1}-m_{2}} \rho_{W}
$$

- open porosity. Samples of volume ca. $10 \mathrm{~cm}^{3}$ have been put in water. The volume of fluid that infiltrates the sample is measured. The porosity of Beaucaire limestone is $14 \pm 1 \%$. For crinoidal limestone, the porosity is less than $1 \%$.

- Young's modulus E, Poisson's ratio $\nu$ and compressive strength $\sigma_{c}$ by performing uniaxial compression experiments. Four specimens $(50 \mathrm{~mm} \times 50$ $\mathrm{mm} \times 100 \mathrm{~mm}$ ) are tested. Two strain rosette are installed.

- longitudinal $c_{L}$ and transverse $c_{T}$ wave velocities evaluated on an ultrasound bench. The same Young's modulus and Poisson's ratio of crinoidal limestone are found from velocity measurements

$$
E=\rho c_{T}^{2} \frac{3 c_{L}^{2}-4 c_{T}^{2}}{c_{L}^{2}-c_{T}^{2}} \quad \text { and } \quad \nu=\frac{c_{L}^{2}-2 c_{T}^{2}}{2\left(c_{L}^{2}-c_{T}^{2}\right)}
$$

Conversely, the Young's modulus and Poisson's ratio of Beaucaire limestone do not follow equations (2) because of porosity.

- Weibull parameters by using three-point bend experiments. To model random failure of the two limestones, which are brittle materials, a Weibull law [23] is used. As rock failure is a random phenomenon, numerous experiments are needed to determine the Weibull parameters. Forty experiments (gauge volume: $50 \mathrm{~mm} \times 50 \mathrm{~mm} \times 150 \mathrm{~mm}$ ) for each limestone are carried out. The outer span is equal to $150 \mathrm{~mm}$ and a special flexural setup was used to control the boundary conditions [24]. The failure probability is written 
as $P_{F}(i)=(i-0.5) / N$, where $N$ is the specimen number $(N=40)$ and $i$ is the number of the specimen corresponding to the $i^{\text {th }}$ lowest failure stress. The failure probability is then compared to that given by a Weibull law

$$
P_{F}=1-\exp \left[-\frac{V_{e f f}}{V_{0}}\left(\frac{\sigma_{F}}{\sigma_{0}}\right)^{m}\right]
$$

where $m$ is the Weibull modulus, $\sigma_{0}$ the scale parameter associated with a reference volume $V_{0}, \sigma_{F}$ the failure stress

$$
\sigma_{F}=\max _{\Omega}\left(\left\langle\sigma_{1}(\mathbf{x})\right\rangle\right)
$$

and $V_{\text {eff }}$ the effective volume [25]

$$
V_{\mathrm{eff}}=\int_{\Omega}\left(\frac{\left\langle\sigma_{1}(\mathbf{x})\right\rangle}{\sigma_{F}}\right)^{m} d \mathbf{x}
$$

associated with the maximum principal stress $\sigma_{1}$ when positive $(\langle\bullet\rangle$ denotes the Macauley brackets). For three-point flexural tests, the effective volume is $V_{\text {eff }}=V / 2(m+1)^{2}$, where $V$ is the loaded volume of the specimen. By using Equation (3) and the expression of the effective volume in three-point flexure, the failure probability $P_{F}$ and the failure stress $\sigma_{F}$ are related by

$$
\ln \left(-\ln \left(1-P_{F}\right)\right)=m \ln \left(\sigma_{F}\right)+\ln \left(\frac{V}{2(m+1)^{2} V_{0} \sigma_{0}^{m}}\right)
$$

Figure 1 allows one to determine the Weibull moduli and scale parameters for the two studied materials. The slope of $\ln \left(\ln \left(-\left(1-P_{F}\right)\right)\right)$ vs $\ln \left(\sigma_{F}\right)$ is $m$. There is a large difference of Weibull modulus between the two limestones, which means that fracture scatter of crinoidal limestone is less than that of Beaucaire limestone.

In the following, the difference in Weibull parameters is analyzed in terms of microstructural differences. From this analysis, a model of microstructure is introduced to describe microstructural defects that are the cause of quasistatic failure and the crack pattern observed under dynamic loading conditions. The Weibull parameters are representative of the material microstructure, and more precisely on the defect distribution and local toughness properties $[26,27]$. The Weibull modulus is mainly related to the decay for large defect sizes of the probability density function, which is usually described by a power law whose exponent is a linear function of the Weibull modulus. Consequently, different Weibull moduli, as observed for the two studied rocks, is an indication of different defect populations, in particular for the largest defect sizes, i.e., the ones likely to initiate failure under quasi-static loading conditions. For a given reference volume $V_{0}$, different stresses $\sigma_{0}$ are mainly induced by different toughnesses and average defect sizes. Different defect populations will 
therefore lead to different Weibull parameters. Conversely, different Weibull parameters are indicators of different defect distributions. When dealing with dynamic fragmentation, the Weibull model itself can no longer be used since a weakest link hypothesis does not apply. However, the following microstructure model using Weibull parameters is considered.

A microstructure model is now introduced to account for random distributions of defects. It has to be valid for describing single and multiple fragmentation regimes. Its advantage then lies in the fact that quasi-static experiments may be used to identify the material parameters. Once they are determined, they are used in a situation in which single fragmentation no longer occurs (e.g., dynamic fragmentation). The material is assumed to contain point defects of density $\lambda_{t}$. Such hypotheses are those of a Poisson point process of intensity $\lambda_{t}[28,29,20]$. Consequently, the probability of finding $\delta$ defects within a uniformly loaded domain $\Omega$ of volume $V$ reads

$$
P(\delta, \Omega)=\frac{\left(\Lambda_{t}\right)^{\delta}}{\delta !} \exp \left(-\Lambda_{t}\right)
$$

so that $\Lambda_{t}$ corresponds to the average number of defects within $\Omega$. By definition, $\Lambda_{t}$ is related to the density $\lambda_{t}$ by $\Lambda_{t}=\lambda_{t} V$ for a uniformly loaded domain. Let us now assume that $\lambda_{t}$ is a function of the applied stress $\sigma_{1}$. The larger the applied stress, the greater the number of defects that will initiate cracks. One possible choice to account for this trend is given by a power law function of the maximum principal stress

$$
\lambda_{t}\left(\sigma_{1}\right)=\frac{1}{V_{0}}\left(\frac{\left\langle\sigma_{1}\right\rangle}{\sigma_{0}}\right)^{m}
$$

where $m$ and $\sigma_{0}^{m} V_{0}$ are interpreted as the Weibull parameters when single fragmentation occurs. By using the weakest link framework [30], the failure probability $P_{F}$ is the probability of finding at least one defect within $\Omega$ when $\sigma_{1} \equiv \sigma_{F}>0$

$$
P_{F}=P(\delta \geq 1, \Omega)=1-P(\delta=0, \Omega)=1-\exp \left[-\frac{V}{V_{0}}\left(\frac{\sigma_{F}}{\sigma_{0}}\right)^{m}\right]
$$

when a uniform stress is applied. If the stress field is heterogeneous, $\Lambda_{t}$ is related to $\lambda_{t}$ by

$$
\Lambda_{t}=\int_{\Omega} \lambda_{t}(\mathbf{x}) \mathrm{d} \mathbf{x}
$$


the failure probability is described by Equation (3), i.e., a Weibull law, and the mean failure stress $\bar{\sigma}_{F}$ is then expressed as

$$
\bar{\sigma}_{F}=\sigma_{0}\left(\frac{V_{0}}{V_{\text {eff }}}\right)^{\frac{1}{m}} \Gamma\left(1+\frac{1}{m}\right)
$$

and describes the fact that the larger the volume the smaller the mean failure stress, $\Gamma$ denotes the gamma function

$$
\Gamma(a)=\int_{0}^{+\infty} t^{a-1} \exp (-t) d t
$$

with $\Gamma(n)=(n-1)$ ! for integers. The Poisson-Weibull model allows one to relate the Weibull parameters to microstructural properties describing the population of initiation sites. The latter is the key for understanding probabilistic features related to the fragmentation of brittle materials.

From the previous results, it is concluded that there is a large difference of Weibull modulus between the two limestones, which means that fracture scatter of crinoidal limestone is less than that of Beaucaire limestone. Figure 1 and Table 1 also show the difference in mean strength. A significant difference of mechanical properties between the two limestones is observed and due to different defect distributions and local toughnesses. Contrary to Beaucaire limestone, crinoidal limestone has high mechanical properties and a low fracture scatter. These differences will have an impact on fragmentation patterns under dynamic load histories as is shown in the next section.

\section{Edge-on impact}

To observe real-time or post-mortem crack patterns under dynamic loading conditions, rocks are loaded by ballistic impact called "Edge-On Impact" (EOI) experiments $[1,4,31]$. During these tests, a cylindrical striker hits a slab on the edge generating an incident wave. In the wake of the incident wave, due to the radial motion of the medium, tensile hoop stresses are induced with a high-strain rate (hundreds or thousands of $\mathrm{s}^{-1}$, depending on striker velocity, thickness of the target, diameter of striker and on the mechanical properties of target and striker materials). Two types of EOI experiments may be performed (Figure 2):

- edge-on impact with observations thanks to an ultra-high speed camera;

- edge-on impact with a sarcophagus to maintain the fragments in place. 
With the first configuration, it is possible to observe the kinetics of the damage process. The inter-frame time needed for the ultra-high speed camera is ca. a few microseconds with ceramic [31] or glass [32] tiles, or few tens of microseconds for rock and concrete slabs. The second configuration allows for a characterization of the crack density in the target at macroscopic or microscopic scales $[20,33]$.

More recently, a new configuration of EOI tests was proposed for an ultrahigh-strength concrete [34,35]. With such a material, the compressive strength (about $200 \mathrm{MPa}$ in uniaxial compression) is not as high as in $\mathrm{SiC}$ ceramics or glass. Therefore, a special device (called dynamic confinement since it acts only during the few microseconds that follow the impact time) was used to avoid or to limit compressive damage. As shown in Figure 2, the device is made of a steel half-cylinder and a tungsten half-shell that are applied to the lateral faces close to the impact point. When the striker hits the target, the lateral expansion due to the Poisson's ratio is prevented in this area inducing a strong increase of pressure. Therefore, the dynamic confinement system allows one to benefit from the strength increase with hydrostatic pressure [36-38], and from the plastic behavior of geomaterials under high confinement level. No confinement is used beyond the area delimited by the half-cylinders to keep a 2D stress state associated with edge-on impacts [39] and to allow for real-time observations.

\subsection{Observation with an ultra-high speed camera}

The striker speed is measured thanks to two diodes located up stream of the target and separated by $50 \mathrm{~mm}$. The flashlight begins with the second diode signal. A conducting film is put on the point of impact to trigger the camera. Test parameters are gathered in Table 2. Pictures do not allow us to observe all cracks that are visible after the test in crinoidal limestone, presumably because their openings are too small. Yet, few radial cracks are visible in Figure 3(a) when $t \geq 40 \mu \mathrm{s}$. Moreover, few circular-front cracks centered on the impact point are seen to emerge $30 \mu$ s after impact when the material beyond the confinement is ejected from the lateral face (observed face). These cracks also called "emerging crack" or "shell cracking" were previously observed during EOI tests performed on ultra-high strength concrete [35]. This cracking pattern is due to unconfined compression beyond the confined area similar to splitting observed in uniaxial compression tests performed on concretes or rocks.

Damage pattern of Beaucaire limestone during EOI test is shown in Fig- 
ure 3(b). As observed with crinoidal limestone, it is composed of radial cracks and emerging cracks visible $10 \mu$ s after impact (Figure 3(b)). However, radial cracks are stopped at this stage and a second large emerging crack is observed $30 \mu$ s after impact (see sketch in Figure 4).

After the experiments, a reconstitution of the impacted tiles enables one to observe the three post-mortem patterns of the three tested configurations, namely, $C_{C U R}^{1}, C_{C U R}^{2}$ and $B_{C U R}^{1}$ (Figures 5(a), 5(b) and 5(c)). As a consequence of the wide extension of the emerging crack (compressive damage) in Beaucaire limestone, only one radial crack is observed. The fragmentation process was restricted to a small area close to the confinement and the radial cracks did not propagate farther. Conversely, several radial cracks are observed in crinoidal limestone. They correspond to a small extension of emerging cracks in $C_{C U R}^{2}$ or the absence of compressive damage concerning the thick tile $\left(C_{C U R}^{1}\right.$ with no emerging cracks).

\subsection{Post-mortem study}

Edge-on impact fully comminutes rocks next to the point of impact. Postmortem studies of this type of impact has to use a so-called sarcophagus to keep the fragments in their initial place. The sarcophagus used for rocks is the same as that used for ceramics [20] and concrete [34] (Figure 2(b)). After the experiments, fragments are coated with an epoxy resin in vacuum. The slabs are cut, then polished to be analyzed with a binocular magnifier or an optical microscope. Few microcracks in test $C_{S A R C O}^{1}$ appear in crinoidal limestone. There are almost only macrocracks as what is observed when rebuilding the tile (Figure 5(a)). Emerging cracks are observed in the communited area for Beaucaire limestone (Figure 6). Numerous microcracks in test $C_{C U R}^{2}$ appear in crinoidal limestone. Their openings are so small that they are difficult to observe. An analysis with an optical microscope allows one to see preferred directions, namely, radial and hoop directions (Figure 7).

Edge-on impact experiments show a significant crushing zone in Beaucaire limestone, then only one crack leads to fracture. Conversely, in crinoidal limestone there is a crushing zone for higher loads and then a multiple fragmentation zone.

\subsection{First summary}

The two main observations are the presence of emerging cracks in the crushing zone for the two rocks and a difference of fragmentation pattern after this area. 
Two reasons may explain this last point. First, this may be due to difference of tensile loading that depends on tile thickness, striker velocity and compressive behavior of the specimen close to the impact point. The second reason may be the effect of microstructure of the two limestones. To analyze these two assumptions, models and simulations are discussed in the next part.

\section{Numerical simulations}

To account for sliding cracks, i.e., when compressive stresses are dominating such as in zones close to the impact point, the overall material behavior is described by plasticity-like models [40-42]. In the present case, it is proposed to use the simplest of them, namely, perfect plasticity. The drawback is that it does account for the pressure effect only indirectly by the value of the yield stress $\sigma_{Y}$, which will be identified by analyzing the size of the comminuted zone. This is the only parameter that will be identified; all the others are directly obtained from the experiments reported in Section 2. The advantage is its simplicity and will allow to compare the identified value to that obtained in uniaxial compression test.

Moreover, material parameters characterized with quasi-static experiments will be used for dynamic simulations. Rate sensitivity of brittle materials under dynamic and uniaxial compression was reported by numerous authors. In particular, beyond strain rate levels of ca. few $\mathrm{s}^{-1}$, a sharp increase of the ultimate strength is observed in rocks [43-45] and concrete materials [46-48]. However, the reason for the increase in strength is not clearly demonstrated and may be due to the radial confinement induced by inertia effects and/or by the intrinsic rate sensitivity of the material. The lateral expansion associated with a non-zero Poisson's ratio is restrained under dynamic loading by inertia effects [49-51]. To explore the confined behavior of geomaterials avoiding the previous phenomenon, confined 1D-strain compression tests (also called quasioedometric compression) were performed on geomaterials $[46,52,53]$ and more recently on a micro-concrete (MB50) [54-56]. During these tests, a cylindrical specimen is encased in a confinement steel ring and is axially loaded. The radial displacement is considerably reduced by the confinement ring and the radial pressure due to inertia is not acting. Tests performed at strain rates up to $220 \mathrm{~s}^{-1}$ showed none significant influence of loading rate on the deviatoric strength (maximum stress difference) and a limited influence of loading rate on the hydrostatic response [56]. Therefore, no strain rate effect is considered to model compressive damage.

To describe the fragmentation due to tensile stresses, the previous part is coupled with a damage model based upon a fragmentation analysis [20]. The general framework is the same as in Section 2, namely, the Poisson-Weibull 
model describing the material microstructure. The main difference is that in the present case, a weakest link hypothesis does not necessarily apply, even though the Weibull parameters are going to be used. The latter are identified by quasi-static experiments (Table 1).

\subsection{Analysis of loading with an elasto-plastic model}

An elasto-plastic model is used in this section. Different configurations of edgeon impact tests are simulated to identify geometrical or material parameters that influence loading. The different material parameters used in the simulations (mass density, Young's modulus, Poisson's ratio and yield stress), are obtained from the earlier rock characterization (Table 1).

\subsubsection{Constitutive model}

The elastic law is first used

$$
\underline{\underline{\sigma}}^{\text {elastic }}=\lambda \operatorname{tr}(\underline{\underline{\epsilon}}) \underline{\underline{I}}+2 \mu \underline{\underline{\epsilon}}
$$

where $\underline{\underline{\sigma}}$ and $\underline{\underline{\epsilon}}$ are the stress and strain tensors, $\lambda$ and $\mu$ Lamé's parameters and $\underline{\underline{I}}$ the identity tensor. Then, the von Mises criterion is tested to know if plastic flow occurs. In the present case, one uses a perfect plasticity model whose yield function is

$$
f=\sigma_{e q}-\sigma_{Y}=0
$$

where $\sigma_{Y}$ is the yield stress and $\sigma_{e q}$ is the equivalent von Mises stress

$$
\sigma_{e q}=\sqrt{\frac{3}{2} \underline{\underline{\sigma}}_{D}: \underline{\underline{\sigma}}_{D}}
$$

where $\underline{\underline{\sigma}}_{D}$ is the deviatoric stress tensor. To define the crushing zone and the fragmentation zones that are observed experimentally, one assumes in the simulations that this transition is the same as between elasticity and plasticity. To evaluate the yield stress, the ultimate compressive strength in quasi-static experiments (here uniaxial compression) is not sufficient because of the difference of strength in uniaxial and confined compression of geomaterials. It follows that, the higher the pressure, the higher the yield strength. Rocks are confined close to the area of impact, that is why the yield stress is tuned by analyzing numerically edge-on impact tests. 


\subsubsection{Simulations}

A first series of simulations consists in comparing the loading between the three tests to know if the difference of fragmentation may be due to difference of loading. Then a yield strength will be tuned in comparison with the experiments. The elasto-plastic parameters used in simulations are gathered in Table 3. The simulations have been performed with the explicit version of the finite element code Abaqus. The elements used are 8-node cubic elements with reduced integration. Only one quarter of the slab is modeled because of symmetry. Three elements are used in the thickness, 40 along the axis of the striker and 80 in the perpendicular direction. The loading is simulated by considering the initial velocity of the striker and Coulomb friction $(f=0.2)$ is added between the striker and the slab. A penalization method is used to simulate contact.

4.1.2.1 Stress history Figures $8(\mathrm{a})$ and $8(\mathrm{~b})$ show that the radial stress is nearly the same between test $C^{1}$ and test $C^{2}$ for a distance of two striker diameters from the impact point. At that distance, the behavior is elastic. In addition, the plastic zone is also equivalent for these two tests. Loading is driven by the yield strength. For a given material, even if the geometry and striker velocity are different (e.g., tests $C^{1}$ and $C^{2}$ ), the compressive stress levels are very close. Yet, the loading rate and the level of the tensile stress are different. For a distance of two striker diameter, the maximum hoop stress rate is ca. $20 \mathrm{MPa} / \mu \mathrm{s}$ for test $C^{1}, 50 \mathrm{MPa} / \mu \mathrm{s}$ for test $C^{2}$ and $2 \mathrm{MPa} / \mu \mathrm{s}$ for test $B^{1}$. Let us note that the (tensile) levels of the hoop stresses (Figure $8(\mathrm{~b})$ ) are very high compared with the quasi-static failure stresses reported in Section 2. Therefore, multiple fragmentation is likely to occur as will be shown in Section 4.2.4.

4.1.2.2 Yield strength Figure 9 compares the radial stress of test $C^{2}$ for a distance of one striker diameter from the impact surface for two different yield strengths. At that distance, the behavior is plastic. The first value of yield strength is equal to the compressive strength and the second one to twice the compressive strength. One observes that the radial stress is doubled (in the same way as the yield strength). This proves again that the stress level is driven by the yield strength. As one observes for a point in the plastic zone, the steady state value of the radial stress is close to the yield strength. The radial stress also increases in the elastic zone when the yield strength increases. The same observation applies for the hoop stress.

To determine the yield strength, the simulated crushing zone is assumed to be the plastic zone. Thus, the crushing zone is represented by the area where 
the von Mises stress reaches the yield strength (in confined compression). A comparison between experimental and simulated crushing zones indicates that twice the uniaxial compressive strength is a good approximation (Figures 10 and 11) to describe confined damage. A ratio of 3 between the compressive strength and the yield strength decreases by $50 \%$ the simulated crushing zone for crinoidal limestone, whereas a ratio of 1.5 increases this area of $20 \%$ for the same material. These percentages are smaller for Beaucaire limestone because of the low level of the compressive strength.

\subsection{Fragmentation law}

Fragmentation is now described by a damage law based on a obscuration mechanism. The Weibull parameters are considered and the other material parameters used to describe damage of the rocks in tension.

\subsubsection{Constitutive model}

When slabs are impacted, damage in tension is observed due to positive hoop stresses induced by the radial motion. Cracks are initiated on defects. Their distribution is described by the Poisson-Weibull model introduced in Section 2. The underlying assumption is that the initiation sites are the same for any load history, be it quasi-static or dynamic. Yet, all defects do not initiate cracks (Figure 7). Close to propagating cracks the stresses are relaxed. One assumes that no cracks are initiated in this obscuration zone [20]. The measure of the obscuration zone is defined as

$$
Z_{o}(T-t)=S[k C(T-t)]^{n}
$$

where $T$ is present time, $t$ the time when the crack appears, $S$ is a shape factor, $C$ is the longitudinal wave velocity, $n$ is the space dimension and $k$ a constant. New cracks will be initiated only outside any of this zone. Therefore, the total flaw density $\lambda_{t}(\sigma(t))$ is split into two parts, namely, $\lambda_{b}(\sigma(t))$, the crack density and the obscured flaw density. The increment of the crack density $\lambda_{b}(\sigma(t))$ is related to that of the total flaw density $\lambda_{t}(\sigma(t))$ by

$$
\frac{d \lambda_{b}}{d t}(\sigma(t))=\frac{d \lambda_{t}}{d t}(\sigma(t))\left[1-P_{o}(T)\right]
$$


where $P_{o}(T)$ is the obscuration probability. The obscuration probability is written as $[20]$

$$
P_{o}(T)=1-\exp \left(-\int_{t=0}^{t=T} \frac{d \lambda_{t}}{d t}(\sigma(t)) Z_{o}(T-t) d t\right)
$$

The obscuration probability $P_{0}$ is the fraction of relaxed zone. That is why one assumes that the obscuration probability corresponds to damage associated with a given propagation direction. Cracking occurs normal to three directions. The compliance $\underline{\underline{\underline{\underline{S}}}}$ is then expressed as [22]

$$
\underline{\underline{\underline{S}}}_{D}=\frac{1}{E}\left[\begin{array}{cccccc}
\frac{1}{1-D_{1}} & -\nu & -\nu & 0 & 0 & 0 \\
-\nu & \frac{1}{1-D_{2}} & -\nu & 0 & 0 & 0 \\
-\nu & -\nu & \frac{1}{1-D_{3}} & 0 & 0 & 0 \\
0 & 0 & 0 & \frac{1+\nu}{\left(1-D_{2}\right)^{\alpha}\left(1-D_{3}\right)^{\alpha}} & 0 & 0 \\
0 & 0 & 0 & 0 & \frac{1+\nu}{\left(1-D_{3}\right)^{\alpha}\left(1-D_{1}\right)^{\alpha}} & 0 \\
0 & 0 & 0 & 0 & 0 & \frac{1+\nu}{\left(1-D_{1}\right)^{\alpha}\left(1-D_{2}\right)^{\alpha}}
\end{array}\right]
$$

where $\alpha=S_{t} / S_{n} \approx 1 / 2$, with $S_{t}$ and $S_{n}$ are shape factors that describe the obscuration zone of tangential and normal stresses. The growth of each damage variable $D_{i}$ is based upon the defect density $\lambda_{t}$ and derived by using equation (18)

$$
\frac{d^{n-1}}{d t^{n-1}}\left(\frac{1}{1-D_{i}} \frac{d D_{i}}{d t}\right)=\lambda_{t}\left(\sigma_{i}(t)\right) n ! S(k C)^{n}
$$

when $d \sigma_{i} / d t \geq 0$ and $\sigma_{i} \geq 0$, where no index summation is used, and $\sigma_{i}$ are the principal stresses.

\subsubsection{Closed-form solutions}

Closed-form solutions for the obscuration probability, the crack density and ultimate tensile strength are briefly recalled [20] by assuming that the stress rate $\dot{\sigma}$ is constant. A dimensionless flaw density $\left(\bar{\lambda}=\lambda / \lambda_{c}\right)$, time $\left(\bar{t}=t / t_{c}\right)$, space measure $\left(\bar{Z}=Z / Z_{c}\right)$ and stress $\left(\bar{\sigma}=\sigma / \sigma_{c}\right)$ are such that

$$
\lambda_{c}=\lambda\left(t_{c}\right) \quad Z_{c}=Z_{o}\left(t_{c}\right) \quad \sigma_{c}=\sigma\left(t_{c}\right)=\dot{\sigma} t_{c}
$$


The characteristic zone $Z_{c}$ contains on average a flaw that may break at the characteristic time $t_{c}$, namely $\lambda_{c} Z_{c}=1$. The characteristic parameters are given by

$$
\begin{array}{r}
t_{c}=\left[\lambda_{0}\left(\frac{\dot{\sigma}}{\sigma_{0}}\right)^{m} S(k C)^{n}\right]^{-\frac{1}{m+n}} \quad, \quad \sigma_{c}=\left[\frac{\sigma_{0}^{m} \dot{\sigma}^{n}}{\lambda_{0} S(k C)^{n}}\right]^{\frac{1}{m+n}} \\
\lambda_{c}=\left[\frac{\lambda_{0} \dot{\sigma}^{m}}{\left(\sigma_{0} k C\right)^{m} S^{m / n}}\right]^{\frac{n}{m+n}}
\end{array}
$$

The obscuration probability is derived from Equation (18)

$$
P_{o b s}(\bar{T})=1-\exp \left\{-B(m, n) \bar{T}^{m+n}\right\}
$$

where $B$ is a modified Euler (beta) function of the first kind

$$
B(m, n)=m \int_{0}^{1} t^{m-1}(1-t)^{n} \mathrm{~d} t=\frac{\Gamma(m+1) \Gamma(n+1)}{\Gamma(m+n+1)}
$$

As mentioned above, the variable $P_{\text {obs }}$ is used to define a damage variable in the framework of Continuum Damage Mechanics. Under dynamic loading conditions, there is a gradual damage growth. $P_{\text {obs }}$ is assumed to be equal to a damage variable $D$. The change of the damage parameter is then given by Equation (23). One observes that $D(\bar{T}=1) \cong 0$ and $D(\bar{T}=2) \cong 1$ (i.e., most of the damage growth occurs during a time interval equal to $t_{\mathrm{c}}$ ). During $t_{\mathrm{c}}$, the horizon is limited by $Z_{\mathrm{obs}}\left(t_{\mathrm{c}}\right)=Z_{\mathrm{c}}$ therefore the minimum measure of the representative zone to consider for the evaluation of the damage variable is $Z_{\mathrm{c}}$. Table 4 compares the characteristic times $t_{c}$ for the three tests. For test $C^{2}$, only $0.47 \mu$ s are needed to damage the considered volume element whereas $1.1 \mu \mathrm{s}$ are necessary for test $C^{1}$. This difference is only due to the stress rate that is greater for test $C^{2}$. Furthermore, $t_{c}=3.4 \mu \mathrm{s}$ for test $B^{1}$; the stress rate is ten times less than that of test $C^{1}$. The Weibull modulus has a significant influence on the fragmentation characteristics. The higher the Weibull modulus, the higher damage kinetics.

By integrating Equation (17) for a constant stress rate, a dimensionless crack density (where only the space dimension $n$, the Weibull modulus $m$ and a dimensionless time $\bar{T}$ are involved) reads

$$
\bar{\lambda}_{b}(\bar{T})=\frac{m}{m+n}[B(m, n)]^{-\frac{m}{m+n}} \gamma\left[\frac{m}{m+n}, B(m, n) \bar{T}^{m+n}\right]
$$


where $\gamma(a, T)$ is the incomplete gamma function

$$
\gamma(a, T)=\int_{0}^{T} t^{a-1} \exp (-t) d t
$$

so that $\gamma(a, T \rightarrow+\infty) \equiv \Gamma(a)$. The crack density at saturation $\bar{\lambda}_{b \infty}$ (i.e., when $\bar{T}$ tends to infinity) reads

$$
\bar{\lambda}_{b \infty}=[B(m, n)]^{-\frac{m}{m+n}} \Gamma\left[\frac{m}{m+n}+1\right]
$$

By using this result, an estimation of the number of cracks in edge-on impacts is performed. The chosen location from the impact point is two striker diameters where the stress rate has been evaluated in Section 4.1.2.1. The crack density is estimated by assuming that the value at saturation is reached. As cracking occurs during $t_{c}$, if the raise duration of the hoop stress is greater than $t_{c}$, the crack density at saturation is reached. Figure $8(\mathrm{~b})$ shows that the time increment for the hoop stress to increase is ca. $5 \mu \mathrm{s}$ for test $C^{1}$, and 3 $\mu \mathrm{s}$ for test $C^{2}$, which is greater than $t_{c}$ (Table 4). It is also the case for test $B^{1}$. The crack density is the product of the normalized crack density at saturation $\bar{\lambda}_{b \infty}$ with the characteristic crack density $\lambda_{c}$ calculated in Table 4 . The crack density is ca. 15 cracks per $\mathrm{mm}^{3}$ for test $C^{1}, 170 \mathrm{~mm}^{-3}$ for test $C^{2}$ and $0.019 \mathrm{~mm}^{-3}$ for test $B^{1}$. The higher the Weibull modulus, the higher the number of cracks at saturation. This result explains the difference of fragmentation pattern for the two rocks (Figures 5(a), 5(b) and 5(c)).

An additional study is now carried out to determine the ultimate strength properties. Under quasi-static loading condition, a Weibull model applies and the mean failure stress depends on the Weibull parameters and the effective volume [see Equation (11)]. These quantities are the key parameters for low stress rates. In particular, no stress rate effect is obtained. Under dynamic loadings, the previous result no longer holds and the afore mentioned damage model applies. By noting that, in pure tension, the macroscopic stress $\Sigma$ is related to the local (or effective) stress $\sigma$ by $\sigma=\Sigma /(1-D)$ [57], the ultimate tensile strength $(\mathrm{d} \Sigma / \mathrm{d} \sigma=0)$, denoted by $\Sigma_{\max }$, is expressed as

$$
\frac{\Sigma_{\max }}{\sigma_{\mathrm{c}}}=[\mathrm{e}(m+n) B(m, n)]^{\frac{-1}{m+n}}
$$

The normalized ultimate strength only depends upon the Weibull modulus $m$ and the space dimension $n$. The ultimate strength itself is then proportional to $\dot{\sigma}^{n /(m+n)}$. This result is in agreement with experimental data of oil shale [17], microconcrete [34,58,59], ceramics and glass [59]. 


\subsubsection{Single and multiple fragmentation regimes}

Equations (11) and (28) define two different regimes. The first one is obtained when a weakest link hypothesis is made. It corresponds to single fragmentation. The second one assumes multiple fragmentation. Figure 12 shows the change of the tensile strength with the stress rate for an effective volume $V_{\text {eff }}$ $(n=3)$ equal to a volume of an element in FE simulations for the two studied materials.

The transition between "quasi-static" and "dynamic" strength is estimated by the intersection between the weakest link and the multiple fragmentation solutions (Figure 12)

$$
\bar{\sigma}_{F}=\Sigma_{\max }(\dot{\sigma})
$$

The transition defined by Equation (29) leads to the following inequalities

$$
\dot{\sigma} \begin{cases}<\dot{\sigma}_{t} & \text { single fragmentation } \\ \geq \dot{\sigma}_{t} & \text { multiple }\end{cases}
$$

with

$$
\dot{\sigma}_{t}=\sigma_{0} k C_{0}\left(\lambda_{0} S\right)^{\frac{1}{n}}\left(V_{e f f} \lambda_{0}\right)^{-\frac{m+n}{m n}}\left[\mathrm{e}(m+n) B(m, n) \Gamma^{m+n}\left(1+\frac{1}{m}\right)\right]^{\frac{1}{n}}
$$

This transition does not only depend on material parameters but also involves the measure $V_{\text {eff }}$ of the considered element. The response of a large structure is "dynamic" for low stress rates even if the material follows a weakest link hypothesis for the same loading applied on a smaller domain.

The "quasi-static" strength $\bar{\sigma}_{F}$ (Table 3 ) is higher for crinoidal limestone than for Beaucaire limestone. $\bar{\sigma}_{F}$ is nearly the same for test $C^{1}$ and test $C^{2}$, even if the effective volume is different. This is due to the high Weibull modulus of crinoidal limestone. Consequently, only one plot represents the two tests in Figure 12. The slope in the log-log plot is $3 /(m+3)$. This means that the stress rate has a higher influence when the Weibull modulus is low. When the stress rate increases from $10 \mathrm{MPa} / \mu$ s to $100 \mathrm{MPa} / \mu \mathrm{s}$, the strength is multiplied by ca. 2.6 for Beaucaire limestone, and 1.3 for crinoidal limestone. Figure 12 shows the different stress rates of each test for distance of two striker diameters. One observes that for this distance, single fragmentation occurs for test $B^{1}$, which is another reason for the presence of only one macrocrack. The weakest link hypothesis is valid in this area. Conversely, multiple fragmentation occurs in 
tests $\mathrm{C}^{1}$ and $\mathrm{C}^{2}$.

\subsubsection{Simulations}

Simulations are performed with the explicit finite element code Abaqus via a VUMAT routine in which the model is implemented. Table 3 shows the parameters used. Different quantities are now analyzed.

4.2.4.1 Damage Figure 13 shows that damage is equal to 1 in a smaller zone next to the impact point in Beaucaire limestone than in crinoidal limestone. A larger experimental damage zone is observed in crinoidal limestone, namely, the multiple fragmentation zone. In Beaucaire limestone, the damage zone is only the crushing zone. The simulations predict nearly the same damage zone for test $C^{1}$ and $C^{2}$, namely the same multiple fragmentation zone.

4.2.4.2 Crack density Simulations show that the crack density is higher in crinoidal limestone than in Beaucaire limestone. This was observed in the experiments and is related to the Weibull modulus $\left(m_{B}=3.8, m_{C}=22.3\right)$. The higher the Weibull modulus, the lower the scatter of failure stresses, the more cracks are observed for the same scale parameter. The crack density is around $6.8 \mathrm{~mm}^{-3}$ for test $C^{1}$, and $14 \mathrm{~mm}^{-3}$ for test $C^{2}$ at a distance of two diameters of striker. The density ratio is around two, whereas it is around ten with the closed-form solution. Moreover the density is lower in simulations. The maximum stress rate was chosen for the closed-form solution, therefore it leads to an overestimation of the crack density. Besides, the comparison cannot be made for Beaucaire limestone because no crack is found at a distance of two diameter of striker in the simulation. Experimental crack density is hard to measure because not all the cracks are visible. Yet experiments and simulations show that the crack density is higher for test $C^{2}$ than test $C^{1}$. Moreover a significant difference is also observed between tests $C^{1}$ and $B^{1}$.

4.2.4.3 Principal stress This stress has to be compared with the mean failure stress $\bar{\sigma}_{F}$ (Figure 12 and Table 3). Simulations show that the principal stress is greater than $22 \mathrm{MPa}$ in the whole tile of crinoidal limestone. Moreover, this stress is of the order of the "dynamic" strength when the stress rate is greater than $10 \mathrm{MPa} / \mu \mathrm{s}$. This means that fragmentation may occur in the whole tile as was observed in experiments. It is not the case with Beaucaire limestone where the principal stress is rapidly less than $14 \mathrm{MPa}$; experiments and simulations are thus consistent. 


\subsection{Discussion}

Experiments show that striker velocity and slab geometry have a more important influence on the size of the crushing zone than on the fragmentation pattern (tests $C^{1}$ and $C^{2}$ ). However, these properties do not change significantly the radial stress levels. Yet, the stress rate is higher when the slab thickness is smaller and the striker travels faster. Stresses are influenced by the yield strength, the higher the yield strength, the higher the stresses. A comparison of the experimental and the simulated crushing zone allows one to identify the best yield stress equivalent to twice the quasi-static compression strength.

Observations of edge-on impacts show that fragmentation is not very different between tests $C^{1}$ and $C^{2}$ whereas simulations find a ratio of around 2 in crack densities in the slab. Yet, experiments show that fragmentation is higher for test $C^{2}$ than test $C^{1}$. The difficulty is to measure experimentally crack densities. However by comparing tests $C^{1}$ and $B^{1}$, experiments and simulations are in good agreement, namely, the higher the Weibull modulus, the higher the crack density. When the Weibull modulus is high, the failure stress scatter is low, defects break and initiate cracks nearly at the same time before slab failure. Conversely, when the Weibull modulus is low, the failure stress scatter is large, few defects break and initiate cracks before slab failure. Moreover, one observes that, contrary to crinoidal limestone, stress rates are too low in the slab of Beaucaire limestone for multiple fragmentation to occur. Consequently, the crack density is lower.

\section{Summary}

Two limestones have been characterized by performing quasi-static mechanical tests. Their behavior is significantly different, crinoidal limestone needs high loads to be cracked and has a high Weibull modulus (i.e., a low scatter in failure stress is observed). Conversely, Beaucaire limestone, which is very porous, has low mechanical properties and a low Weibull modulus. The Weibull parameters are therefore the key quantities for characterizing quasistatic and dynamic fragmentation of different rocks.

Edge-on impacts allow one to identify a predominant factor in rock fragmentation, namely, the Weibull modulus. Numerous cracks are observed when the Weibull modulus is high. Moreover, two regimes have been identified, namely, single and multiple fragmentation. The difference of crack density is also due to lower stress rates in the Beaucaire limestone slab. It does not permit mul- 
tiple fragmentation to occur. A crushing zone is observed for higher loads in crinoidal limestone than in Beaucaire limestone, which is consistent with mechanical properties. In this area emerging cracks are observed. This zone is driven by the yield strength accounting for compressive damage.

Simulations of these experiments show that the fragmentation model is able to capture the experimental observations. Damage and crack densities calculated are consistent with experimental fragmentation patterns. However, the way the yield strength is identified is not completely satisfactory. A new model better accounting for confined damage has to be written to have a better simulation of energy levels in the crushing zone. Next, blast experiments will be performed to study the corresponding fragmentation.

\section{Acknowledgements}

The authors wish to thank F. Didier, F. Penquer and L. Taravella from CTAArcueil for their help in performing edge-on impacts, B. Raka and X. Pinelli from LMT-Cachan for their help in the characterization experiments.

\section{References}

[1] E. Strassburger, H. Senf and H. Rothenhäusler, Fracture Propagation during Impact in Three Types of Ceramics, J. Physique IV coll. C8 [suppl. IV] (1994) 653-658.

[2] P. C. den Reijer, Impact on Ceramic Faced Armor, (PhD thesis, Delft Technical University, 1991).

[3] L. Beylat and C. E. Cottenot, Post Mortem Microstructural Characterization of $\mathrm{SiC}$ Materials after Interaction with a Kinetic Energy Projectile, Proceedings SUSI'96 symposium, (1996), 459-468.

[4] U. Hornemann, J. F. Kalthoff, H. Rothenhäusler, H. Senf and S. Winkler, Experimental Investigation of Wave and Fracture Propagation in Glass - Slabs Loaded by Steel Cylinders at High Impact Velocities, (EMI report E 4/84, Weil am Rhein (Germany), 1984).

[5] J. Cagnoux, Déformation et ruine d'un verre pyrex soumis à un choc intense : étude expérimentale et modélisation du comportement, (Thèse d'Etat, University of Poitiers, 1985).

[6] J. S. Rinehart, Dynamic Fracture Strengths of Rocks, Proceedings 7th Symp. Rock Mech., (1965). 
[7] H. K. Kutter and C. Fairhurst, On the Fracture Process in Blasting, Int. J. Rock Mech. Min. Sci. 8 (1971) 181-202.

[8] D. A. Shockey, D. R. Curran, L. Seaman, J. T. Rosenberg and C. F. Petersen, Fragmentation of Rocks under Dynamic Loads, Int. J. Rock Mech. Min. Sci. 11 (1974) 303-317.

[9] R. P. Kennedy, A Review of Procedures for the Analysis and Design of Concrete Structures to Resist Missile Impact Effects, Nucl. Eng. Des. 37 (1976) 183-203.

[10] N. F. Mott, Fragmentation of Shell Cases, Proc. Roy. Soc. Lond A189 (1947) 300-308.

[11] D. E. Grady and M. E. Kipp, Geometric Statistics and Dynamic Fragmentation, J. Appl. Phys. 58 [3] (1985) 1210-1222.

[12] N. Kusano, T. Aoyagi, J. Aizawa, H. Ueno, H. Morikawa and N. Kobayashi, Impulsive Local Damage Analysis of Concrete Structure by the Distinct Finite Element Method, Nuclear Eng. Design 138 (1992) 105-110

[13] G. T. Camacho and M. Ortiz, Computational Modelling of Impact Damage in Brittle Materials, Int. J. Solids Struct. 33 [20-22] (1996) 2899-2938.

[14] S. Mastilovic and D. Krajcinovic, High-Velocity Expansion of a Cavity within a Brittle Material, J. Mech. Phys. Solids 47 (1999) 577-600.

[15] F. Zhou and J. F. Molinari, Stochastic Fracture of Ceramics under Dynamic Tensile Loading, Int. J. Solids Struct. 41 (2004) 6573-6596.

[16] H. D. Espinosa, P. D. Zavattieri and S. K. Dwivedi, A Finite Deformation Continuum/Discrete Model for the Description of Fragmentation and Damage in Brittle Materials, J. Mech. Phys. Solids 46 (1998) 1909-1942.

[17] D. E. Grady and M. E. Kipp, Continuum Modeling of Explosive Fracture in Oil Shale, Int. J. Rock Min. Sci. \& Geomech. Abstr. 17 (1980) 147-157.

[18] L. G. Margolin, Elasticity Moduli of a Cracked Body, Int. J. Fract. 22 (1983) 65-79.

[19] A. M. Rajendran, Modeling the Impact Behavior of AD85 Ceramic under Multiaxial Loading, Int. J. Impact Eng. 15 [6] (1994) 749-768.

[20] C. Denoual and F. Hild, A Damage Model for the Dynamic Fragmentation of Brittle Solids, Comp. Meth. Appl. Mech. Eng. 183 (2000) 247-258.

[21] W. Benz and E. Asphaug, Impact Simulations with Fracture. I. Method and Tests. Icarus 107 (1994) 98-116.

[22] C. Denoual and F. Hild, Dynamic Fragmentation of Brittle Solids: a Multi-Scale Model. European J. Mechanics A/Solids 41 (2002) 105-120.

[23] W. Weibull, A Statistical Theory of the Strength of Materials, (Roy. Swed. Inst. Eng. Res., Report 151, 1939). 
[24] J.-M. Robin, Y. Berthaud, N. Schmitt, J. Poirier and D. Themines, Thermomechanical Behaviour of Magnesia Carbon Refractory Ceramics, Brit. Ceram. Trans. 97 (1998) 1-10.

[25] D. G. S. Davies, The Statistical Approach to Engineering Design in Ceramics, Proc. Brit. Ceram. Soc. 22 (1973) 429-452.

[26] A. de S. Jayatilaka and K. Trustrum, Statistical Approach to Brittle Fracture, J. Mater. Sci. 12 (1977) 1426-1430.

[27] F. Hild and D. Marquis, A Statistical Approach to the Rupture of Brittle Materials, Eur. J. Mech., A/Solids 11 [6] (1992) 753-765.

[28] R. Gulino and S. L. Phoenix, Weibull Strength Statistics for Graphite Fibres Measured from the Break Progression in a Model Graphite/Glass/Epoxy Microcomposite, J. Mater. Sci. 26 [11] (1991) 3107-3118.

[29] D. Jeulin, Modèles morphologiques de structures aléatoires et changement d'échelle, (PhD thesis, University of Caen, 1991). See also C. Baxevanakis, D. Jeulin and D. Valentin, Fracture Statistics of Single-Fiber Composite Specimens, Comp. Sci. Tech. 48 (1993) 47-56.

[30] A. M. Freudenthal, Statistical Approach to Brittle Fracture, Fracture, $H$. Liebowitz, Edt., Academic Press, New York 2 (1968) 591-619.

[31] P. Riou, C. Denoual and C. E. Cottenot, Visualization of the Damage Evolution in Impacted Silicon Carbide Ceramics, Int. J. Impact Eng. 21 [4] (1998) 225235 .

[32] X. Brajer, P. Forquin, R. Gy and F. Hild, The Role of Surface and Volume Defects in the Fracture of Glass under Quasi-Static and Dynamic Loading, $J$. of Non-Crystalline Solids 316 (2003) 42-53.

[33] P. Forquin, L. Tran, P.-F. Louvigné, L. Rota and F. Hild, Effect of Aluminum Reinforcement on the Dynamic Fragmentation of SiC Ceramics, Int. J. Impact Eng. 28 (2003) 1061-1076.

[34] P. Forquin, Endommagement et fissuration de matériaux fragiles sous impact balistique, rôle de la microstructure, (PhD thesis, Ecole Normale Supérieure de Cachan, 2003).

[35] P. Forquin and F. Hild, Dynamic Fragmentation of an Ultra-High Strength Concrete during Edge-On Impact Tests, ASCE J. Eng. Mech. [accepted] (2007).

[36] M. Sari and C. Karpuz, Rock Variability and Establishing Confining Pressure Levels for Triaxial Tests on Rocks, Int. J. Rock Mech. Min. Sci. 43 (2006) 328-335.

[37] H. B. Li, J. Zhao and T. J. Li, Triaxial Compression Tests on a Granite at Different Strain Rates and Confining Pressures, Int. J. Rock Mech. Min. Sci. 36 (1999) 1057-1063. 
[38] H. B. Li, J. Zhao, J. R. Li, Y. Q. Liu and Q. C. Zhou, Experimental Studies on the Strength of Different Rock Types Under Dynamic Compression, Int. J. Rock Mech. Min. Sci. 41 (2004) 147-159.

[39] C. Denoual, C. E. Cottenot and F. Hild, On the Identification of Damage during Impact of a Ceramic by a Hard Projectile, Proceedings 16th International Conference on BALLISTICS, (APDS, Arlington (USA), 1996), 541-550.

[40] D. C. Drucker and W. Prager, Soil Mechanics and Plastic Analysis of Limit Design, Quat. of Appl. Math. 14 (1956).

[41] S. Andrieux, Y. Bamberger and J.-J. Marigo, Un modèle de matériau microfissuré pour les bétons et les roches, J. Méc. Th. Appl. 5 [3] (1986) 471-513.

[42] A. Burr, F. Hild and F. A. Leckie, Micro-Mechanics and Continuum Damage Mechanics, Arch. Appl. Mech. 65 [7] (1995) 437-456.

[43] R. J. Christensen, S. R. Swansow and W. S. Brown, Split Hopkinson Bar Test on Rock Under Confining Pressure, Exp. Mech. 12 (1972) 508-541.

[44] U. S. Lindholm, L. M. Yeakley and A. Nagy, The Dynamic Strength and Fracture Properties of Dressel Basalt, Int. J. Rock Mech. Min. Sci. 11 (1974) 181-199.

[45] J. R. Klepaczko, G. Gary and P. Barberis, Behaviour of Rock Salt in Uniaxial Compression at Medium and High Strain Rates, Archives of Mechanics, Warsawa (1991) 499-517.

[46] L. E. Malvern, D. A. Jenkins, T. Tang and S. McLure, Dynamic Testing of Laterally Confined Concrete, Micromechanics of failure of quasi brittle materials, Elsevier Applied Science (1991) 343-352.

[47] T. Tang, L. E. Malvern and D. A. Jenkins, Rate Effects in Uniaxial Dynamic Compression of Concrete, J. Eng. Mech. 118 (1992) 108-124.

[48] G. Gary and H. Zhao, Measurements of the Dynamic Behaviour of Concrete under Impact Loading, Chinese Journal Mechanics Press, Proceedings of 2nd ISIE'96, Beijing (China) (1996) 208-213.

[49] E. D. H. Davies and S. C. Hunter, The Dynamic Compression Testing of Solids by the Method of the Split Hopkinson Pressure Bar, J. Mech. Phys. Solids 11 (1963) 155-179.

[50] L. D. Bertholf and J. Karnes, Two-dimensional Analysis of the Split Hopkinson Pressure Bar System, J. Mech. Phys. Solids 23 (1975) 1-19.

[51] D. A. Gorham, Specimen Inertia in High Strain-rate Compression, J. Phys. D. Appl. Phys. 22 (1989) 1888-1893.

[52] A. M. Bragov, G. M. Grushevsky and A. K. Lomunov, Use of the Kolsky Method for Studying Shear Resistance of Soils, J. Physique IV coll. C8 [suppl. IV] (1994) 253-259. 
[53] J. F. Semblat, G. Gary and M. P. Luong, Dynamic Response of Sand Using 3D Hopkinson Bar, Proceedings of IS-TOKYO'95 First International Conference on Earthquake Geotechnical Engineering, Tokyo (Japan) (1995) .

[54] F. Gatuingt, Prévision de la rupture des ouvrages en béton sollicités en dynamique rapide, (PhD thesis, Ecole Normale Supérieure de Cachan, 1999).

[55] N. Burlion, G. Pijaudier-Cabot and N. Dahan, Experimental Analysis of Compaction of Concrete and Mortar, Int. J. Numer. Anal. Meth. Geomec. 25 (2001) 467-486.

[56] P. Forquin, G. Gary and F. Gatuingt, A Testing Technique for Concrete under Confinement at High Rates of Strain, Int. J. Impact Eng. [accepted] (2007).

[57] Y. N. Rabotnov, Creep Problems in Structural Members, (North-Holland, Amsterdam (the Netherlands), 1969).

[58] A. Brara and J. Klepaczko, An Experimental Method for Dynamic Tensile Testing of Concrete by Spalling, Int. J. Impact Eng. 25 (2001) 387-409.

[59] F. Hild, X. Brajer, C. Denoual and P. Forquin, On the ProbabilisticDeterministic Transition Involved in a Fragmentation Process of Brittle Materials, Comput. Struct. 81 [12] (2003) 1241-1253.

[60] L. Grare, Approche numérique de l'abattage des roches, (BSc report, Ecole Normale Supérieure de Cachan, 2002).

[61] S. Grange, Fragmentation dynamique des roches, (BSc report, Ecole Normale Supérieure de Cachan, 2004). 


\section{List of Tables}

1 Mechanical properties of Beaucaire and crinoidal limestones $[60,61]$.

2 Test parameters. The index $C U R$ indicates that an ultra-high speed camera was used. A sarcophagus configuration is referred to as $S A R C O$. Two different materials are tested (crinoidal (C) and Beaucaire (B) limestones).

3 Simulation parameters. Two different materials are tested (crinoidal (C) and Beaucaire (B) limestones). The yield stress $\sigma_{Y}$ is the only tuned parameter in the simulations.

4 Characteristic parameters. Two different materials are tested (crinoidal (C) and Beaucaire (B) limestones). 


\section{List of Figures}

1 Weibull plot of the two studied limestones by using three-point bend experiments.

2 Schematic of half section of the two configurations of edge-on impact.

3 Ultra-high speed camera observations for two tests (see Table 2).

4 Sketch of damage pattern for the two rocks.

5 Tile fragments observed for three tests (see Table 2).

6 Post-mortem observations of Beaucaire limestone (test $\left.B_{S A R C O}^{1}\right)$.

7 Post-mortem observations of crinoidal limestone close to impact (test $C_{S A R C O}^{2}$ ).

8 Loading of test $C^{1}$ and $C^{2}$ at two striker diameters from the impact point. At that distance, the behavior is elastic.

9 Radial stress for two yield strength at one striker diameter from the impact point for test configuration $C^{2}$. At that distance, the behavior is plastic.

10 Comparaison of the crushing zone size between experiments (a) and simulation (b) for Beaucaire limestone (test $B^{1}$ ). A good agreement is observed.

11 Comparaison of the crushing zone size between experiments (a) and simulation (b) for crinoidal limestone (test $C^{2}$ ). A good agreement is observed.

12 Tensile strength vs. stress rate for the two studied limestones. The curves are obtained by using Equations (11) and (28) where $V_{\text {eff }}$ is the volume of an element. The stress rates for a distance of two striker diameter are noticed.

13 Prediction of damage associated with the maximum principal stress for the three tests at the end of impact. 
Table 1

Mechanical properties of Beaucaire and crinoidal limestones [60,61].

\begin{tabular}{|c|c|c|}
\hline material & Beaucaire limestone & crinoidal limestone \\
\hline designation & B & C \\
\hline density: $\rho$ & $2230 \pm 30 \mathrm{~kg} \cdot \mathrm{m}^{-3}$ & $2700 \pm 30 \mathrm{~kg} \cdot \mathrm{m}^{-3}$ \\
\hline Young's modulus: $E$ & $6.04 \pm 0.05 \mathrm{GPa}$ & $77.82 \pm 0.04 \mathrm{GPa}$ \\
\hline Poisson's ratio: $\nu$ & $0.343 \pm 0.003$ & $0.28 \pm 0.02$ \\
\hline compressive strength: $\bar{\sigma}_{c}$ & $10.8 \pm 0.4 \mathrm{MPa}$ & $147 \pm 5 \mathrm{MPa}$ \\
\hline Weibull modulus: $m$ & $3.8 \pm 0.5$ & $22.3 \pm 0.1$ \\
\hline Scale parameter: $\sigma_{0}$ when $V_{0}=1 \mathrm{~cm}^{3}$ & $5 \pm 2 \mathrm{MPa}$ & $18.6 \pm 0.7 \mathrm{MPa}$ \\
\hline effective volume: $V_{e f f}$ & $8200 \pm 1000 \mathrm{~mm}{ }^{3}$ & $360 \pm 70 \mathrm{~mm}{ }^{3}$ \\
\hline longitudinal wave velocity: $c_{L}$ & $3400 \pm 200 \mathrm{~m} . \mathrm{s}^{-1}$ & $6300 \pm 200 \mathrm{~m} . \mathrm{s}^{-1}$ \\
\hline transverse wave velocity: $c_{T}$ & $2100 \pm 200 \mathrm{~m} . \mathrm{s}^{-1}$ & $3350 \pm 200 \mathrm{~m} . \mathrm{s}^{-1}$ \\
\hline
\end{tabular}

Table 2

Test parameters. The index $C U R$ indicates that an ultra-high speed camera was used. A sarcophagus configuration is referred to as $S A R C O$. Two different materials are tested (crinoidal $(\mathrm{C})$ and Beaucaire (B) limestones).

\begin{tabular}{|c|c|c|c|c|c|c|}
\hline Test \# & $C_{C U R}^{1}$ & $C_{S A R C O}^{1}$ & $C_{C U R}^{2}$ & $C_{S A R C O}^{2}$ & $B_{C U R}^{1}$ & $B_{S A R C O}^{1}$ \\
\hline & \multicolumn{6}{|c|}{ TILE } \\
\hline material & \multicolumn{4}{|c|}{ crinoidal limestone } & \multicolumn{2}{|c|}{ Beaucaire limestone } \\
\hline height (mm) & \multicolumn{6}{|c|}{300} \\
\hline length $(\mathrm{mm})$ & \multicolumn{6}{|c|}{150} \\
\hline \multirow[t]{2}{*}{ thickness (mm) } & \multicolumn{2}{|c|}{15} & \multicolumn{2}{|r|}{8} & \multicolumn{2}{|r|}{12} \\
\hline & \multicolumn{6}{|c|}{ STRIKER } \\
\hline material & \multicolumn{6}{|c|}{ aluminum } \\
\hline diameter $(\mathrm{mm})$ & \multicolumn{6}{|c|}{20} \\
\hline length (mm) & \multicolumn{6}{|c|}{50} \\
\hline \multirow[t]{2}{*}{ striker velocity $\left(\mathrm{m} \cdot \mathrm{s}^{-1}\right)$} & 102 & 98 & 200 & 204 & 101 & 90 \\
\hline & \multicolumn{6}{|c|}{ CONFINEMENT } \\
\hline material & \multicolumn{6}{|c|}{ tungsten } \\
\hline diameter $(\mathrm{mm})$ & \multicolumn{6}{|c|}{24} \\
\hline length (mm) & \multicolumn{6}{|c|}{30} \\
\hline
\end{tabular}


Table 3

Simulation parameters. Two different materials are tested (crinoidal $(\mathrm{C})$ and Beaucaire (B) limestones). The yield stress $\sigma_{Y}$ is the only tuned parameter in the simulations.

\begin{tabular}{|c|c|c|c|}
\hline Test \# & $C^{1}$ & $C^{2}$ & $B^{1}$ \\
\hline material & \multicolumn{2}{|c|}{ crinoidal limestone } & Beaucaire limestone \\
\hline striker velocity $\left({\mathrm{m} . \mathrm{s}^{-1}}^{-1}\right.$ & 100 & 200 & 100 \\
\hline & \multicolumn{3}{|c|}{ Elastic properties } \\
\hline$E(\mathrm{GPa})$ & 78 & 78 & 6 \\
\hline$\nu$ & 0.28 & 0.28 & 0.34 \\
\hline$k$ & 0.38 & 0.38 & 0.38 \\
\hline$S$ & 3.74 & 3.74 & 3.74 \\
\hline & & Weibull properties \\
\hline$m$ & 22.3 & 22.3 & 3.8 \\
\hline$V_{e f f}\left(\mathrm{~mm}{ }^{3}\right)$ & 17 & 9.1 & 14 \\
\hline $\bar{\sigma}_{F}(\mathrm{MPa})$ & 21.8 & 22.4 & 14 \\
\hline \hline & \multicolumn{3}{|c|}{ Yield stress } \\
\hline$\sigma_{Y}(\mathrm{MPa})$ & 294 & 294 & 22 \\
\hline
\end{tabular}

Table 4

Characteristic parameters. Two different materials are tested (crinoidal (C) and Beaucaire (B) limestones).

\begin{tabular}{|c|c|c|c|}
\hline Test \# & $C^{1}$ & $C^{2}$ & $B^{1}$ \\
\hline material & \multicolumn{2}{|c|}{ crinoidal limestone } & Beaucaire limestone \\
\hline$\dot{\sigma}(\mathrm{MPa} / \mu \mathrm{s})$ & 20 & 50 & 2 \\
\hline$t_{c}(\mu \mathrm{s})$ & 1.1 & 0.47 & 3.4 \\
\hline$\sigma_{c}(\mathrm{MPa})$ & 21 & 24 & 6.8 \\
\hline$\lambda_{c}\left(\mathrm{~m}^{-3}\right)$ & $1.7 \times 10^{7}$ & $1.9 \times 10^{8}$ & $3.2 \times 10^{6}$ \\
\hline $\bar{\lambda}_{b \infty}$ & 910 & 910 & 6.1 \\
\hline
\end{tabular}




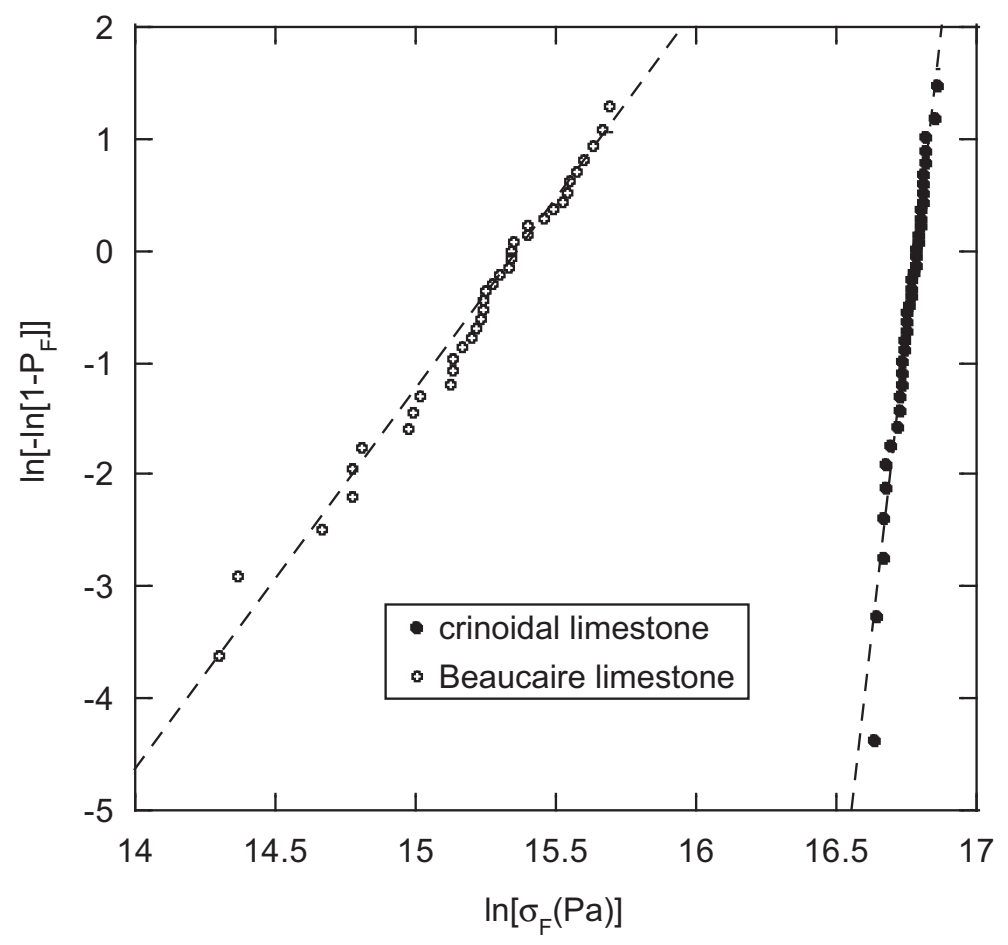

Fig. 1. Weibull plot of the two studied limestones by using three-point bend experiments. 


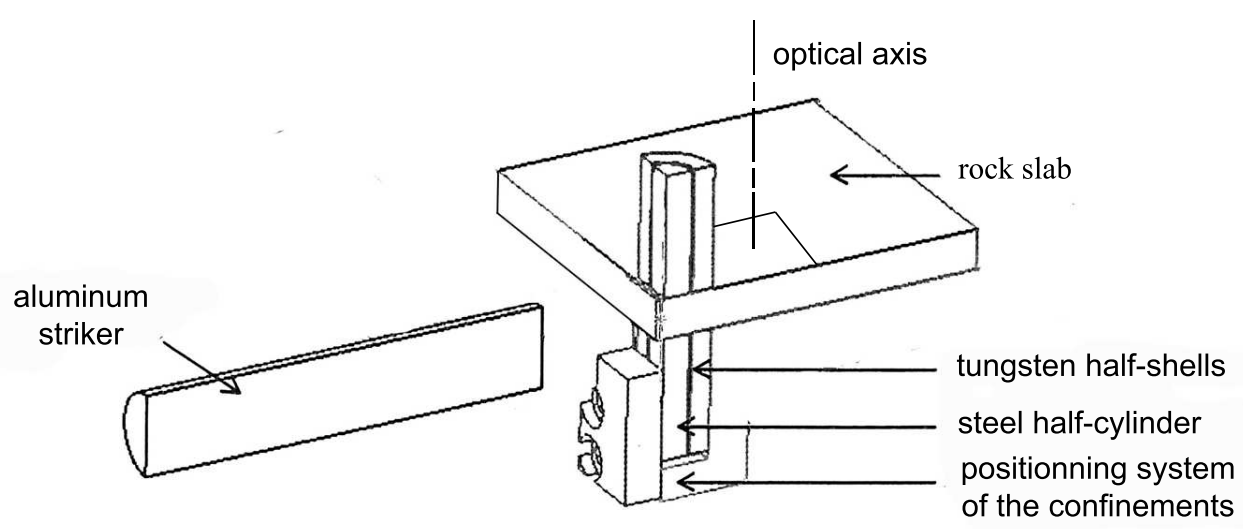

(a) High speed camera observation.

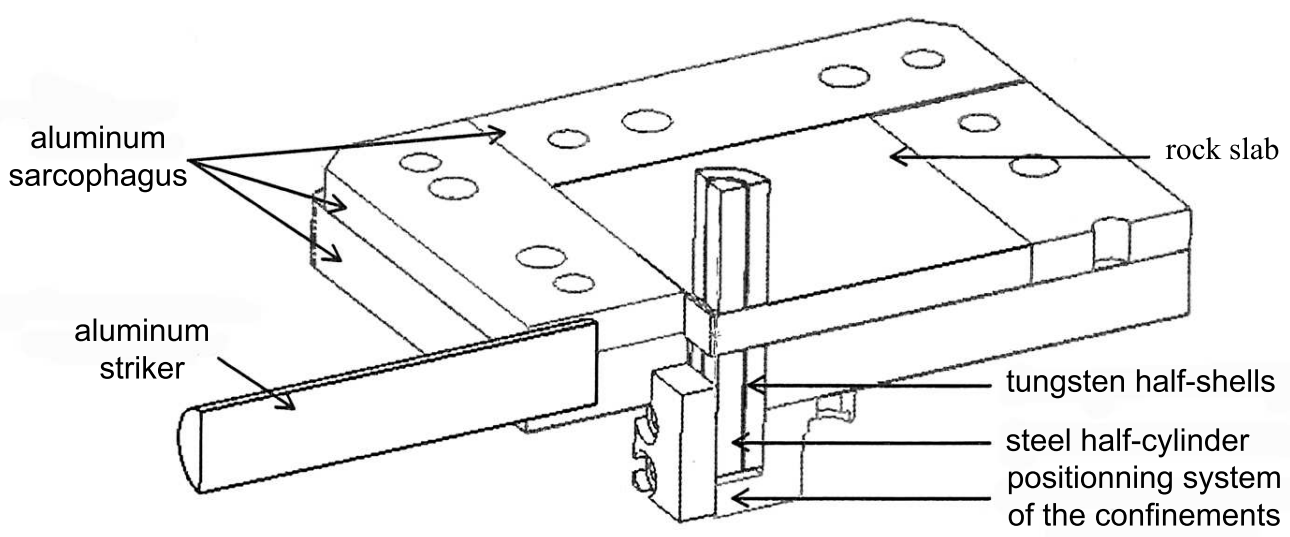

(b) sarcophagus configuration.

Fig. 2. Schematic of half section of the two configurations of edge-on impact. 


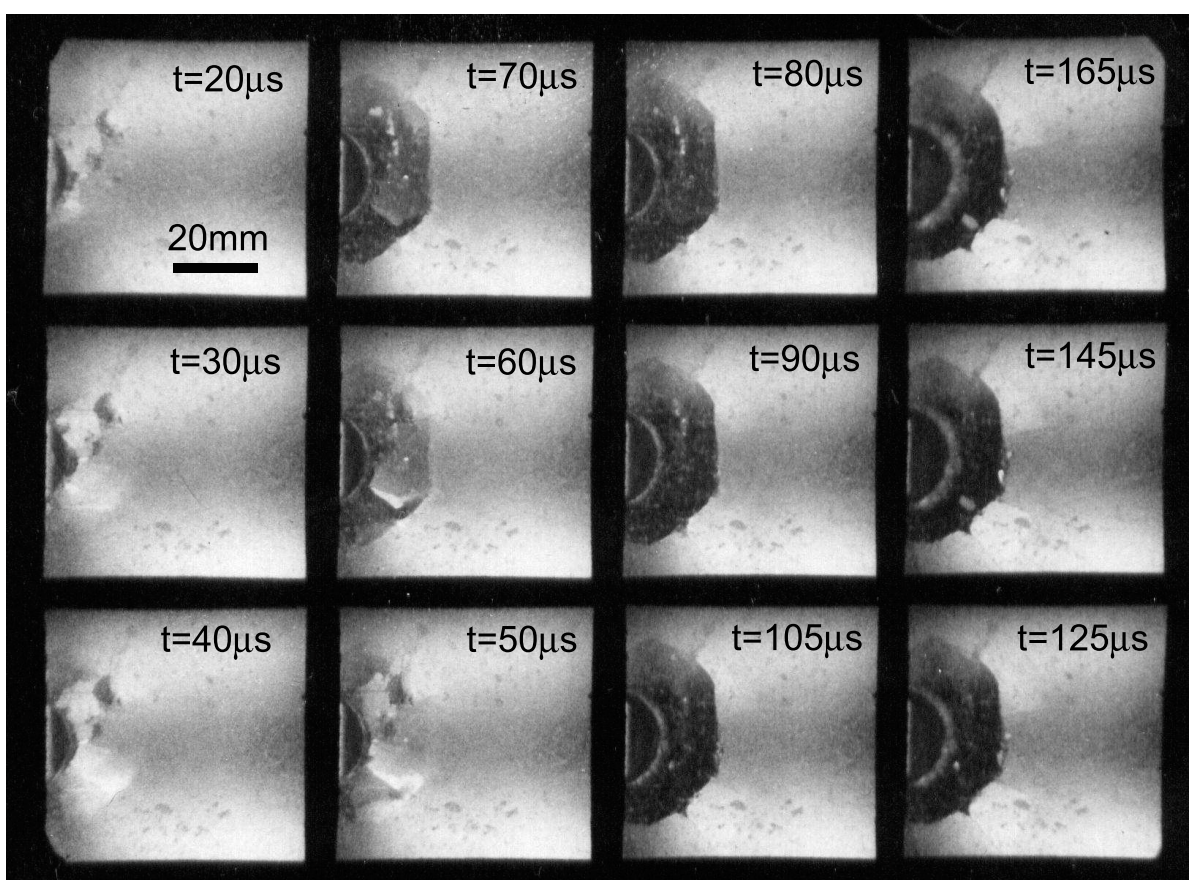

(a) Test $C_{C U R}^{2}$ (crinoidal limestone).

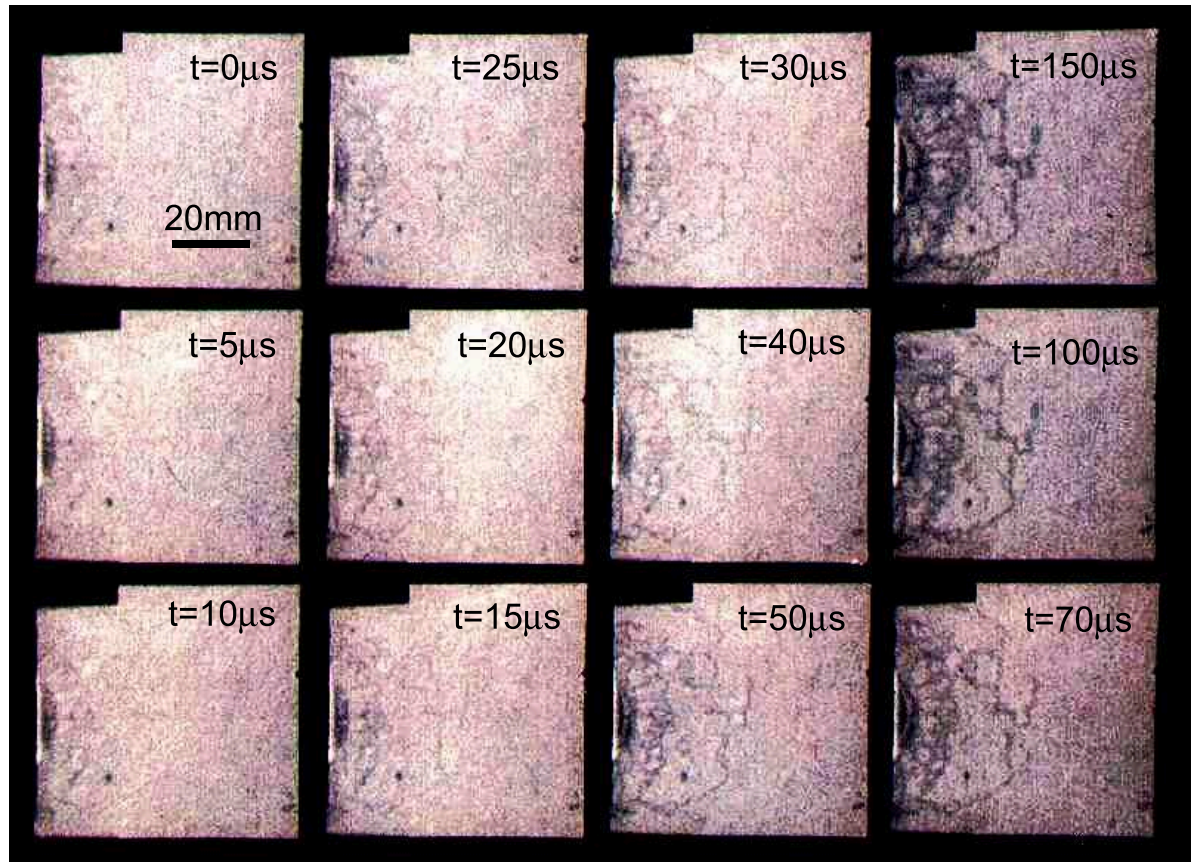

(b) Test $B_{C U R}^{1}$ (Beaucaire limestone).

Fig. 3. Ultra-high speed camera observations for two tests (see Table 2). 


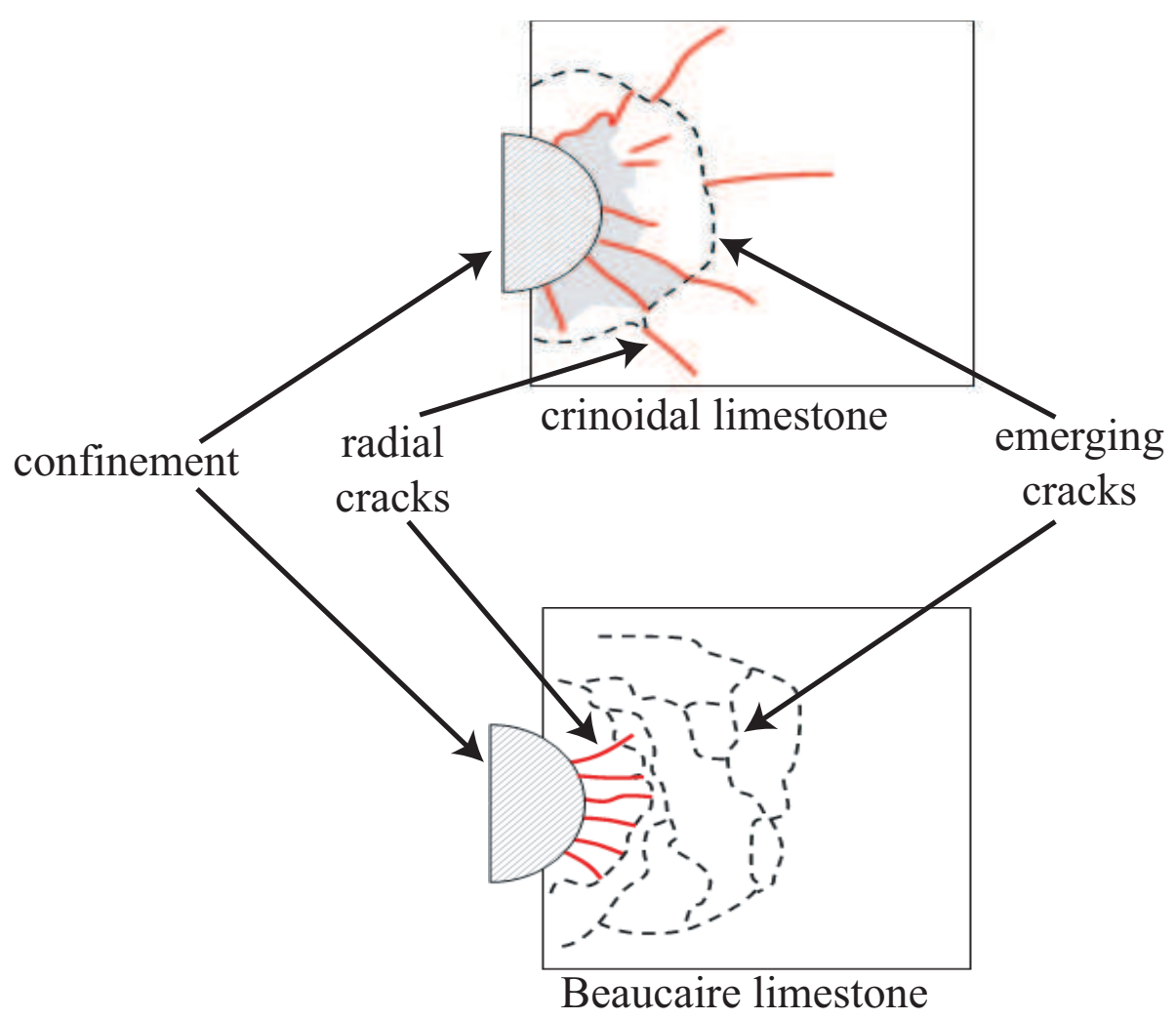

Fig. 4. Sketch of damage pattern for the two rocks. 


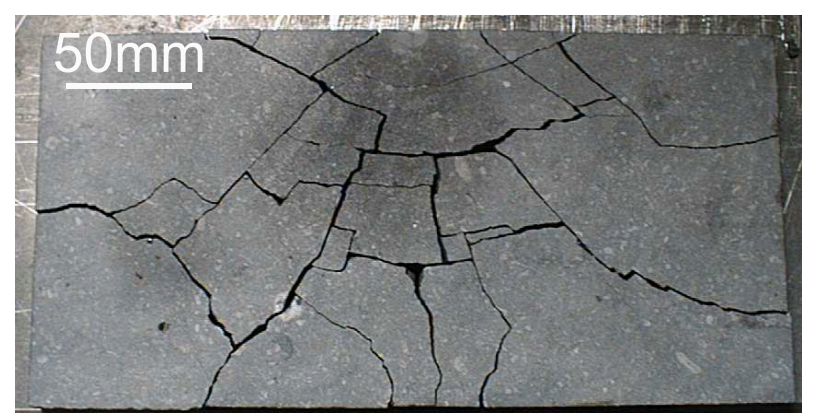

(a) Test $C_{C U R}^{1}$ (crinoidal limestone).

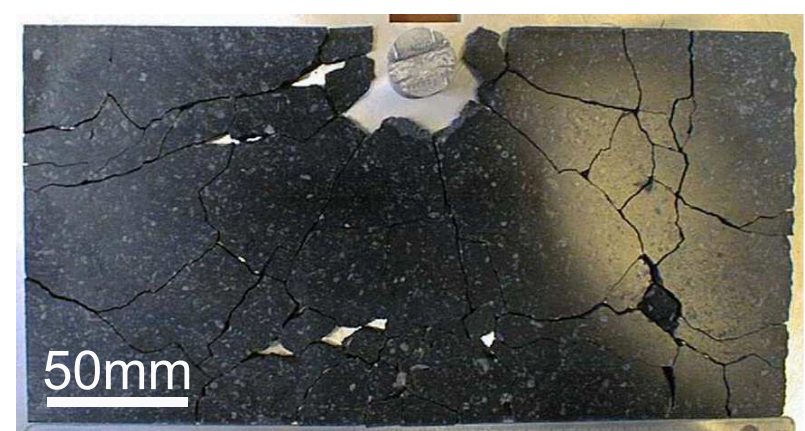

(b) Test $C_{C U R}^{2}$ (crinoidal limestone).

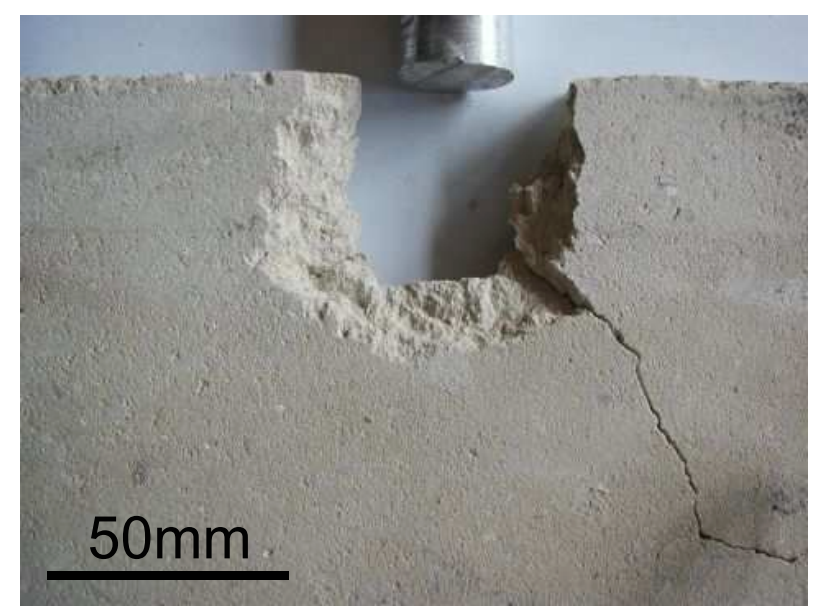

(c) Test $B_{C U R}^{1}$ (Beaucaire limestone).

Fig. 5. Tile fragments observed for three tests (see Table 2). 


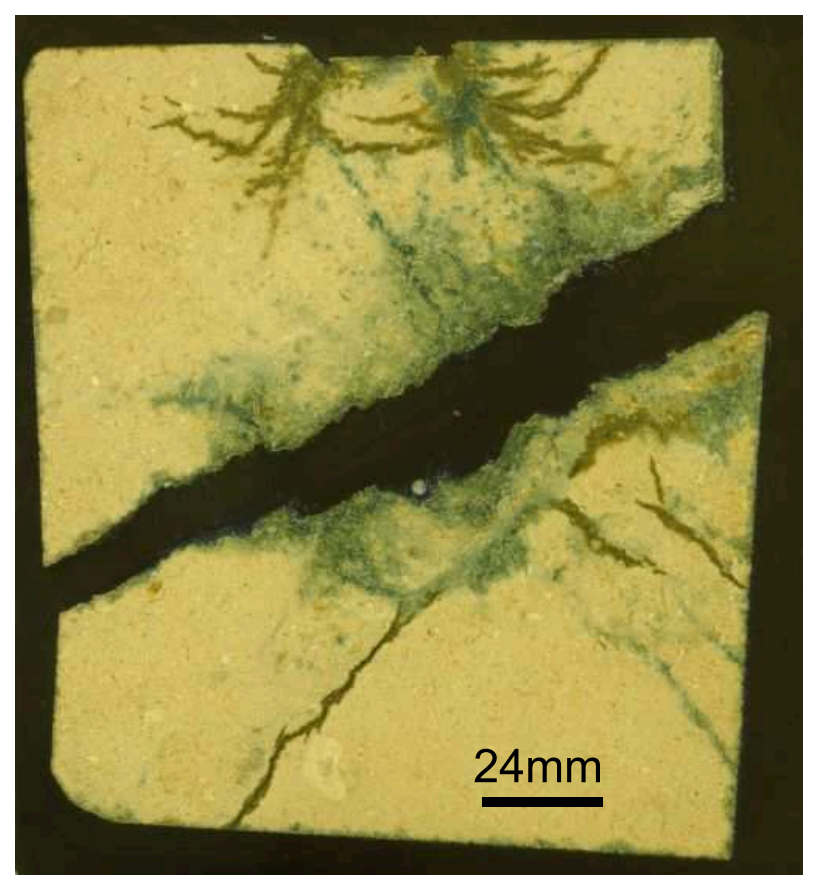

(a) Analysis of the complete tile.

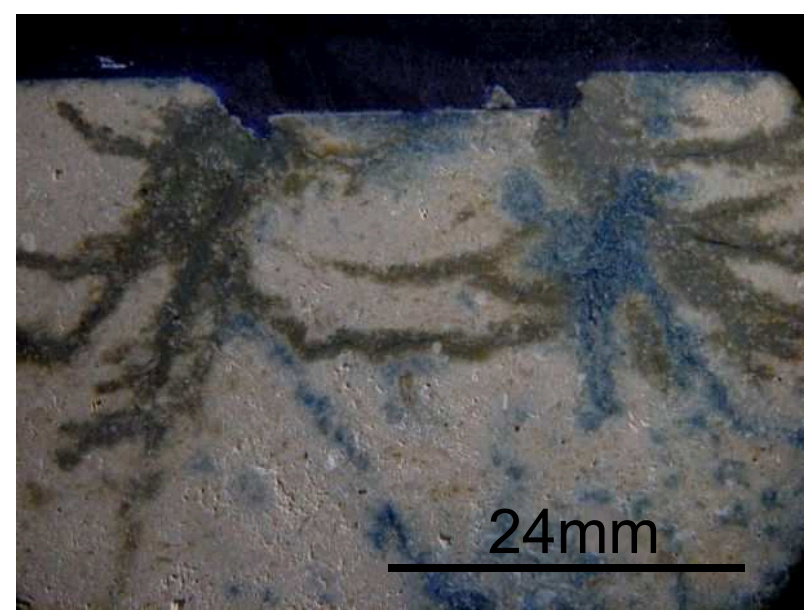

(b) Zoom next to the crushing zone.

Fig. 6. Post-mortem observations of Beaucaire limestone (test $B_{S A R C O}^{1}$ ). 


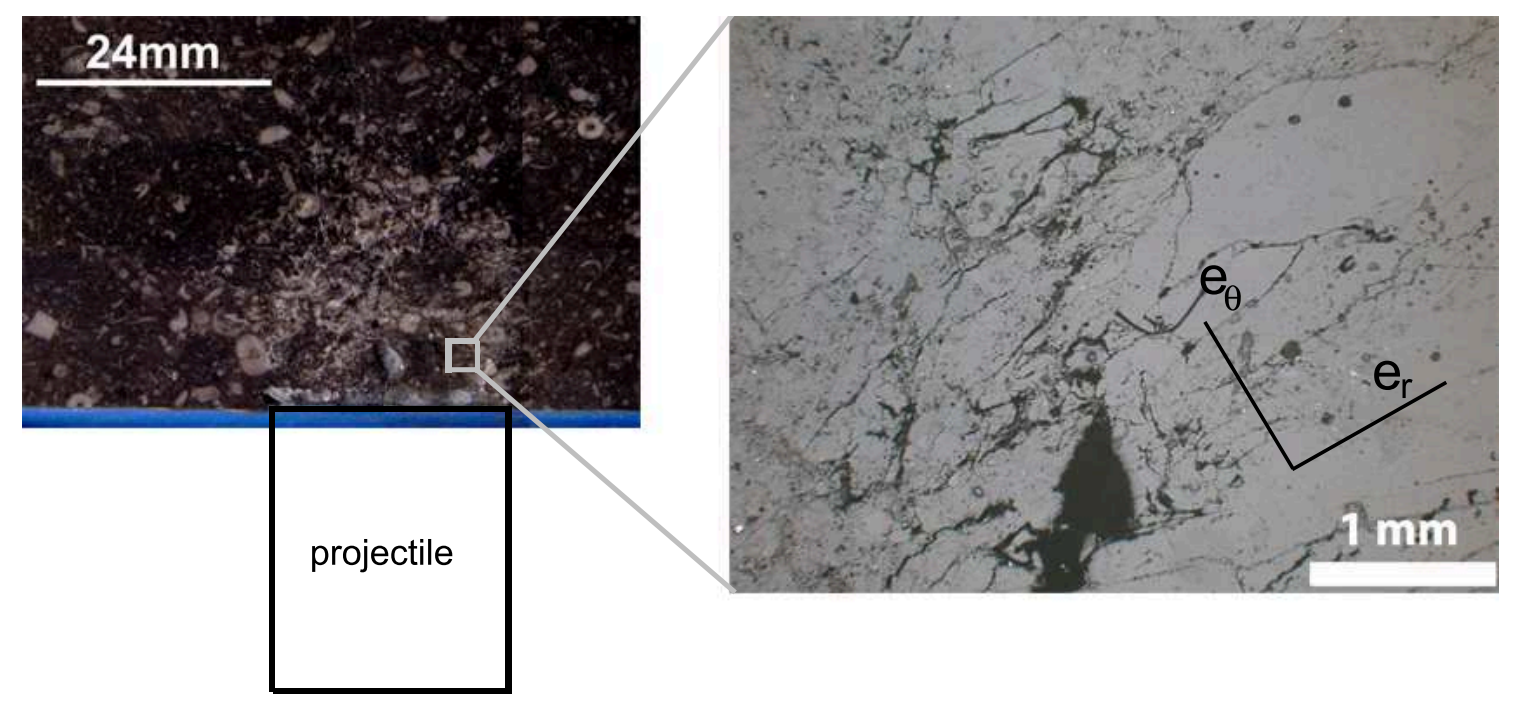

Fig. 7. Post-mortem observations of crinoidal limestone close to impact (test $C_{S A R C O}^{2}$ ). 


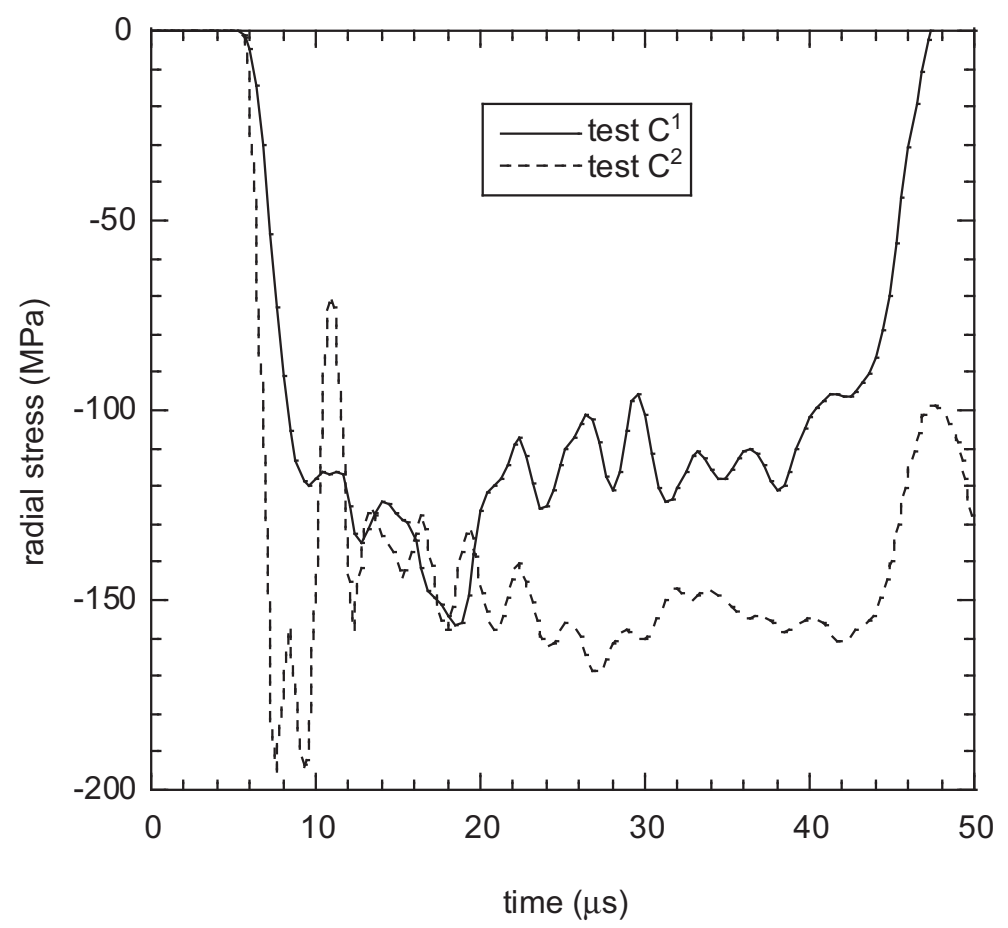

(a) Radial stress.

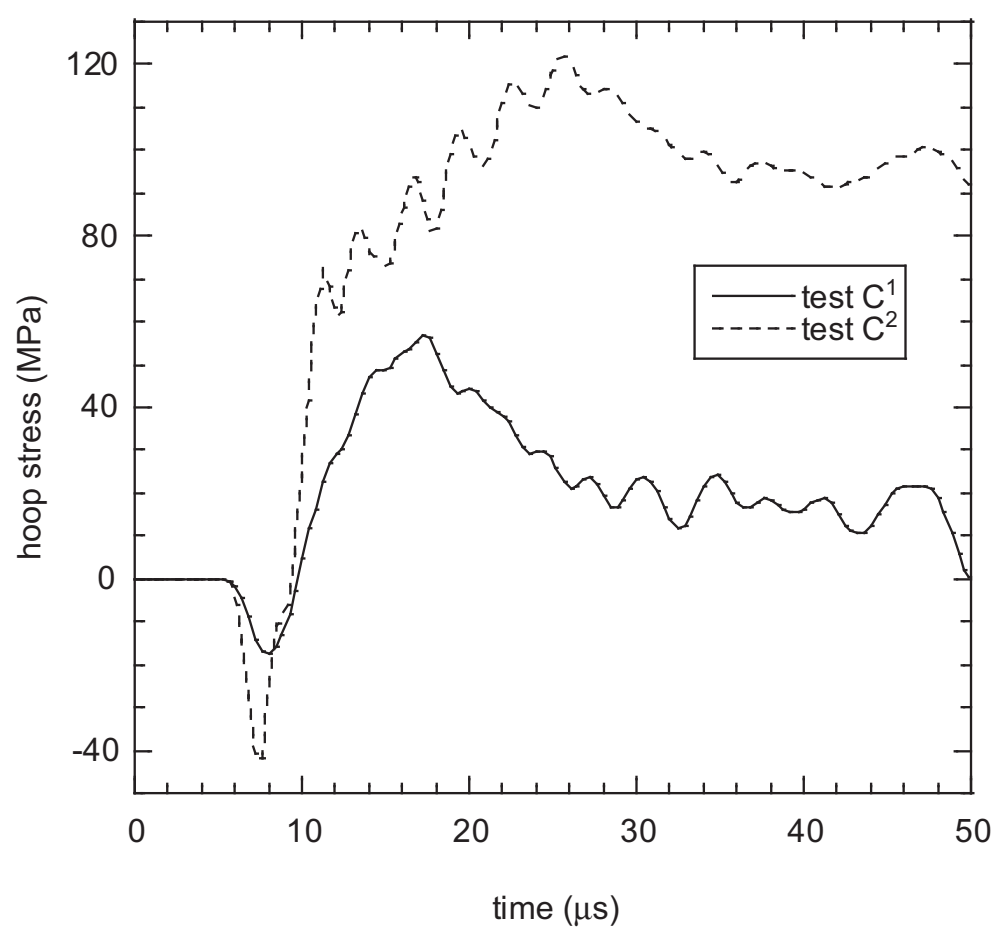

(b) Hoop stress.

Fig. 8. Loading of test $C^{1}$ and $C^{2}$ at two striker diameters from the impact point. At that distance, the behavior is elastic. 


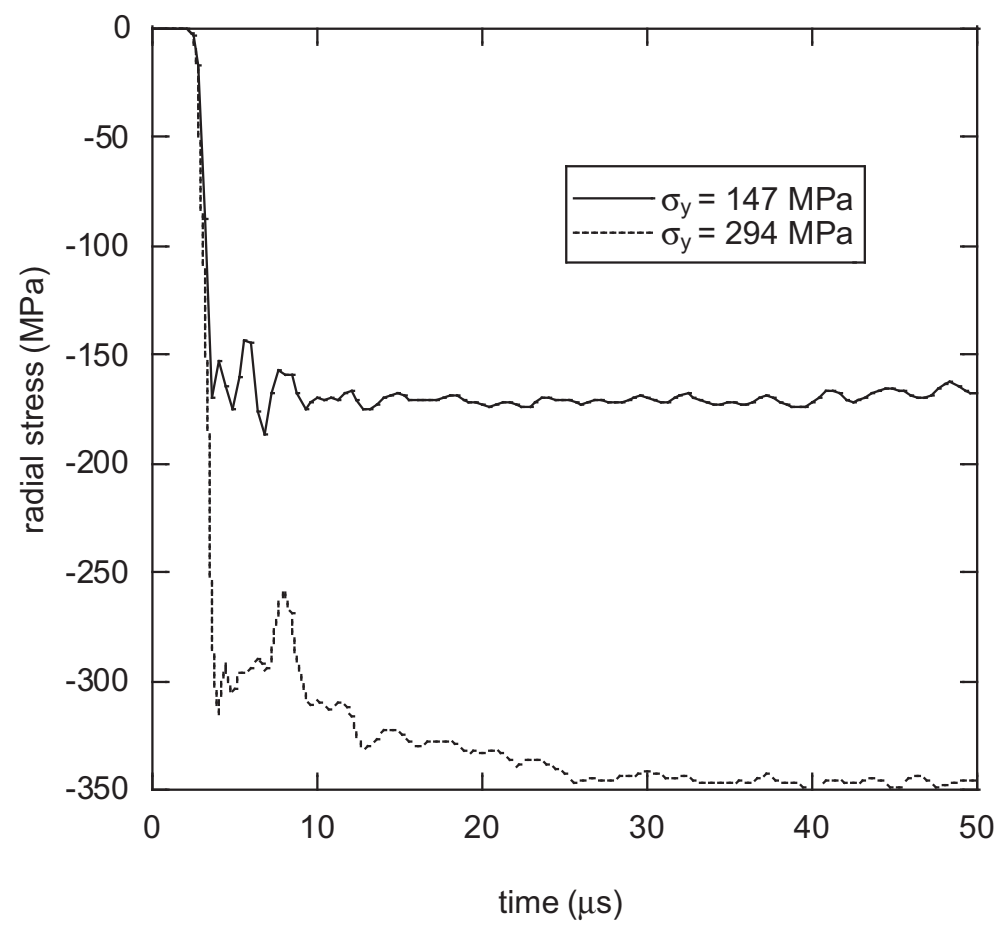

Fig. 9. Radial stress for two yield strength at one striker diameter from the impact point for test configuration $C^{2}$. At that distance, the behavior is plastic. 


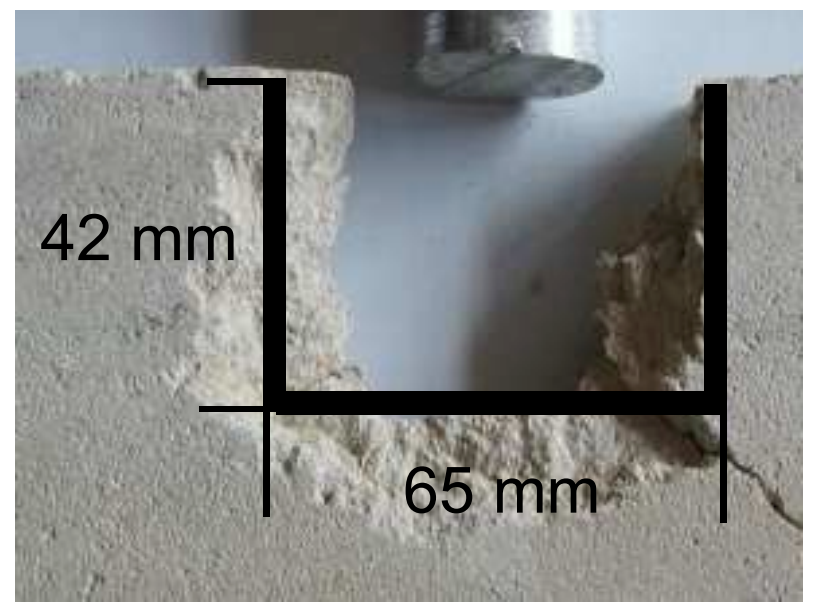

(a) Post-mortem observation.

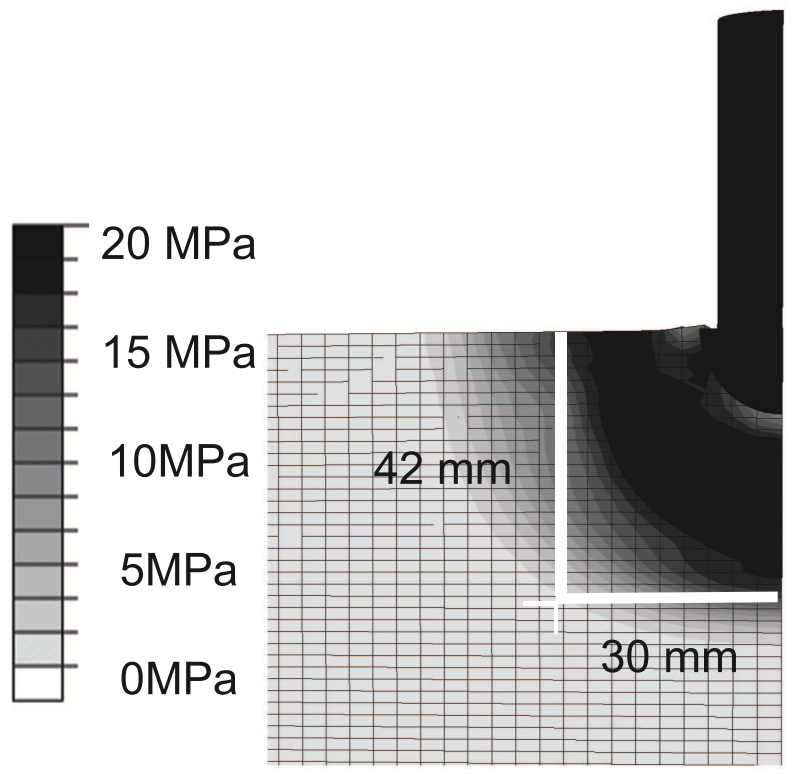

(b) Von Mises stress contours $17 \mu$ s after impact $(\mathrm{MPa})$.

Fig. 10. Comparaison of the crushing zone size between experiments (a) and simulation (b) for Beaucaire limestone (test $B^{1}$ ). A good agreement is observed. 


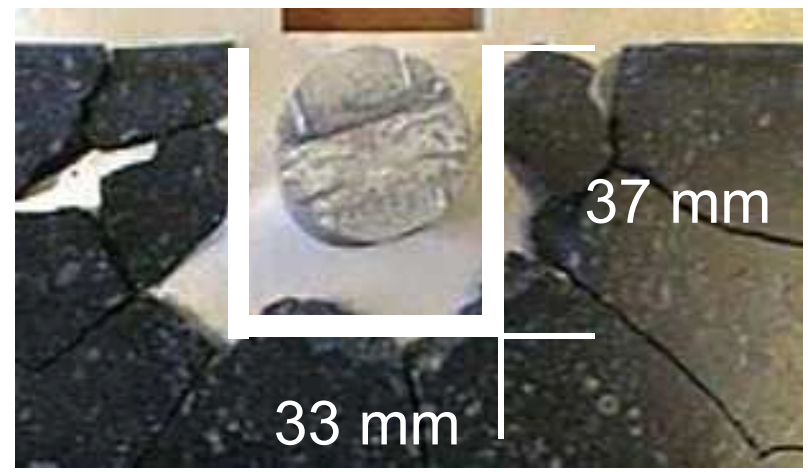

(a) Post-mortem observation.

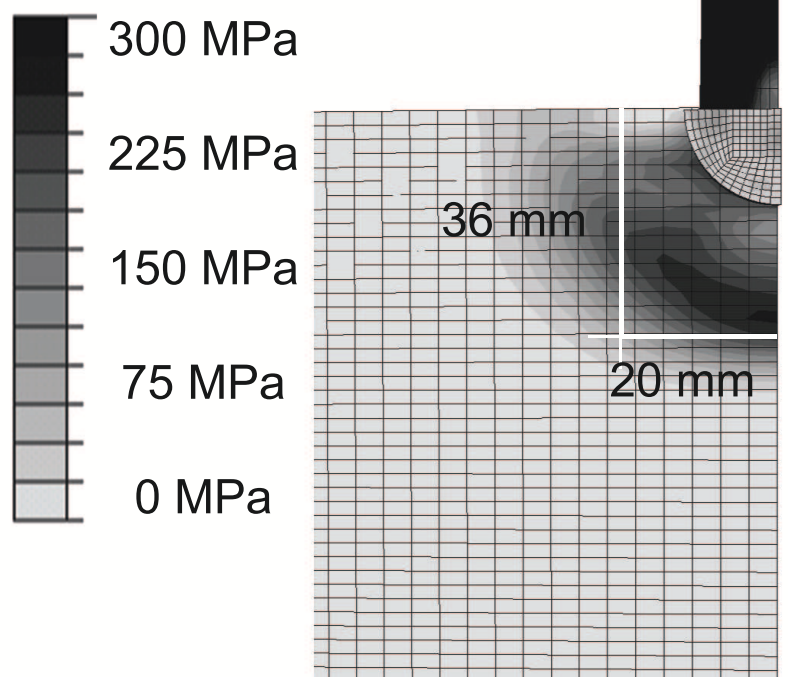

(b) Von Mises stress contours $5.5 \mu$ s after impact (MPa).

Fig. 11. Comparaison of the crushing zone size between experiments (a) and simulation (b) for crinoidal limestone (test $C^{2}$ ). A good agreement is observed. 


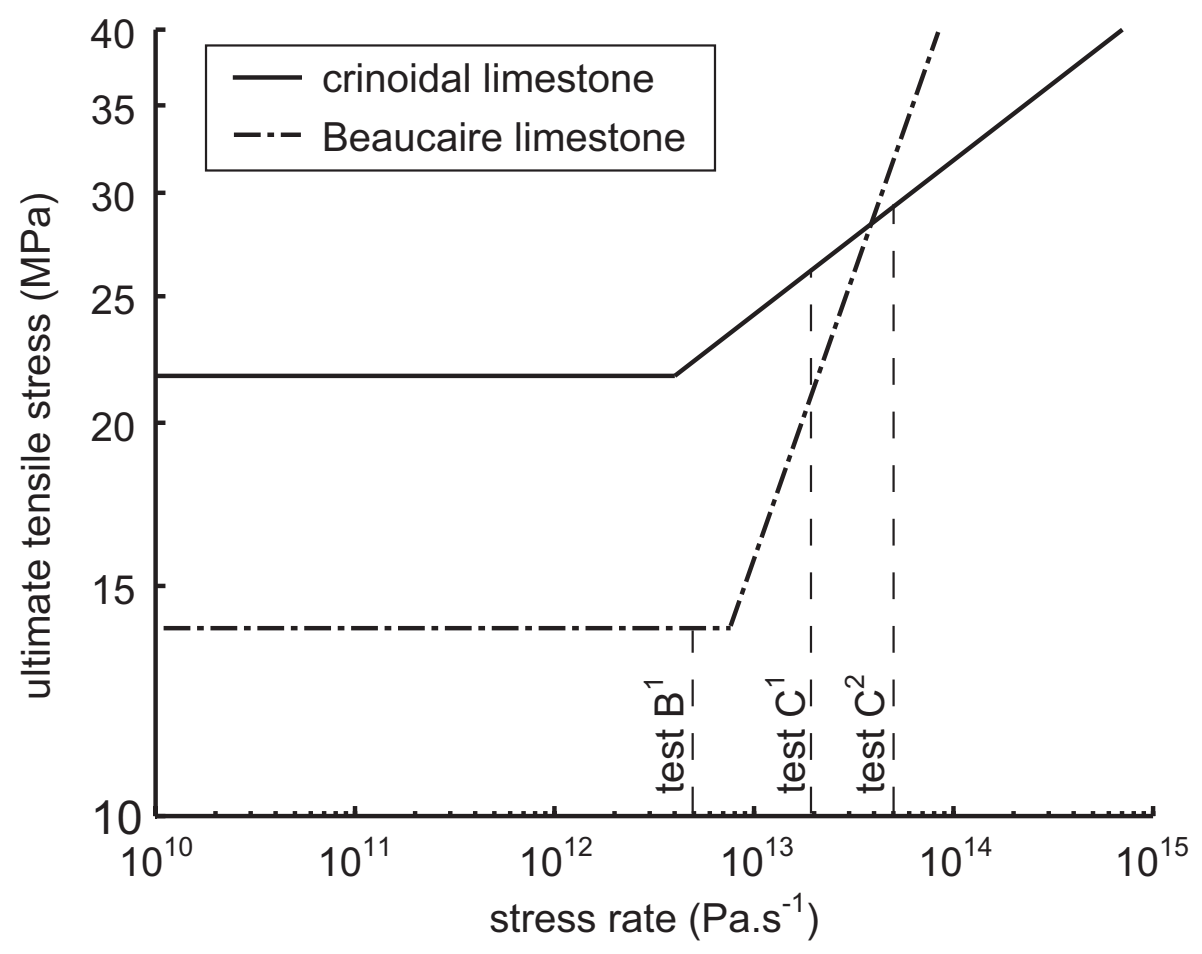

Fig. 12. Tensile strength vs. stress rate for the two studied limestones. The curves are obtained by using Equations (11) and (28) where $V_{\text {eff }}$ is the volume of an element. The stress rates for a distance of two striker diameter are noticed. 


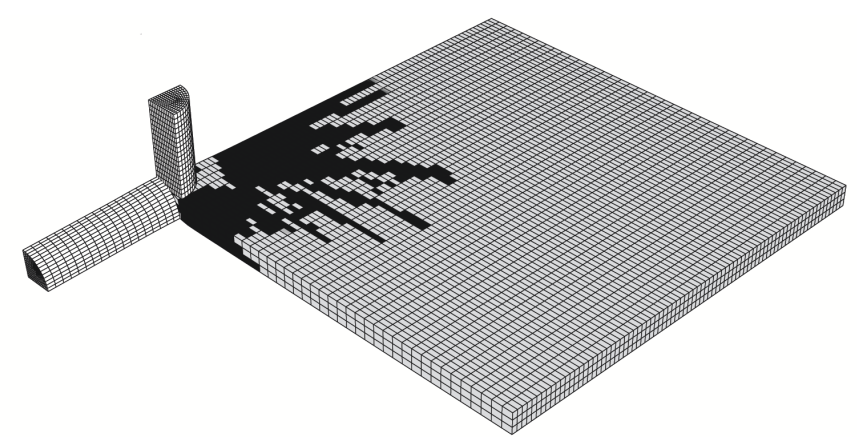

(a) Test $C^{1}$ (crinoidal limestone) $(25 \mu \mathrm{s}$ after impact).

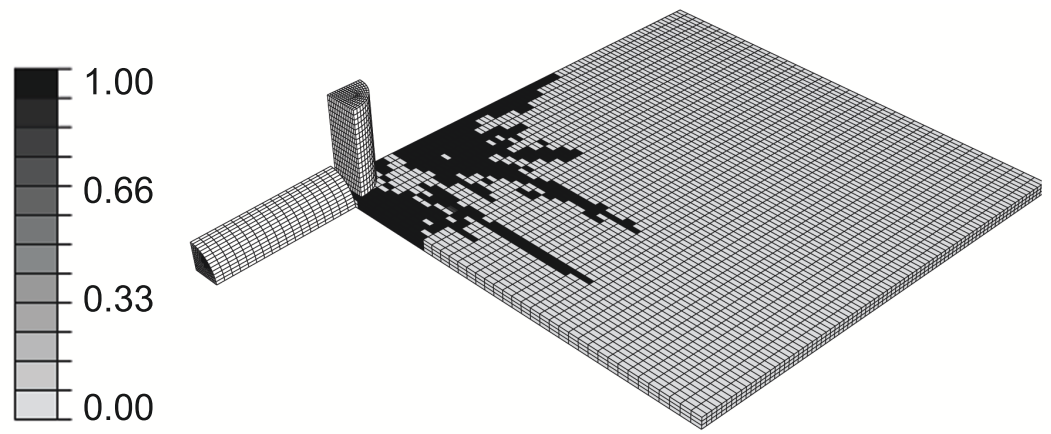

(b) Test $C^{2}$ (crinoidal limestone) (25 $\mu$ s after impact).

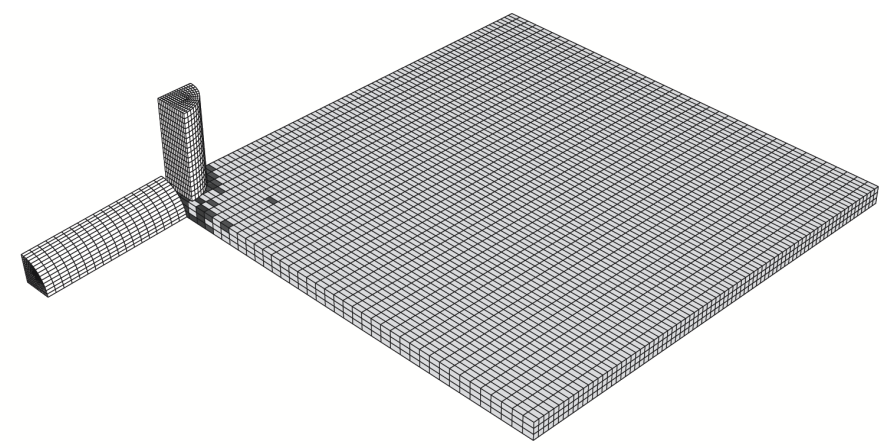

(c) Test $B^{1}$ (Beaucaire limestone) (50 $\mathrm{s}$ after impact).

Fig. 13. Prediction of damage associated with the maximum principal stress for the three tests at the end of impact. 